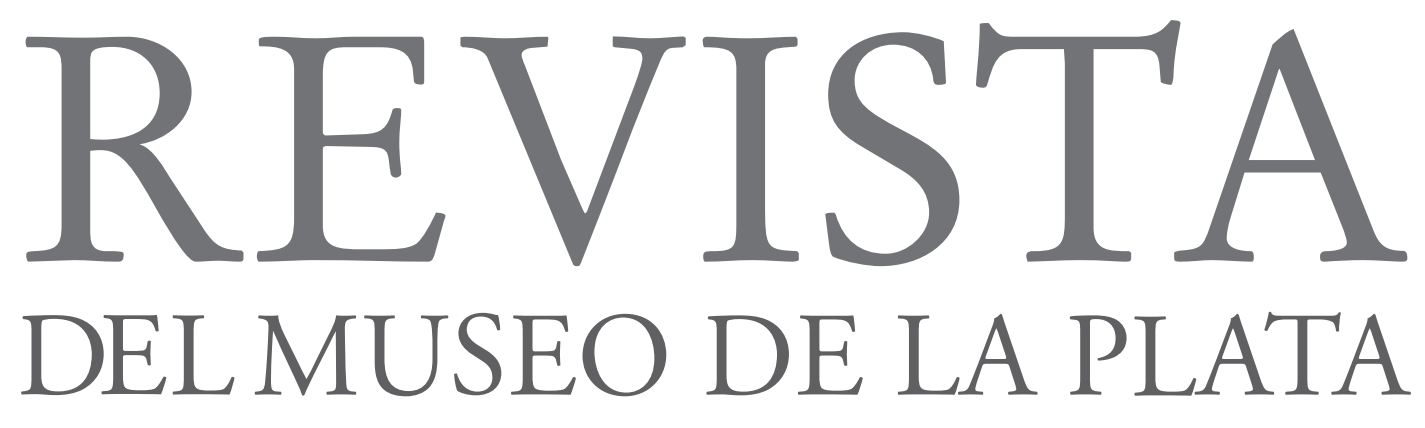

UNLP | Facultad de Ciencias Naturales y Museo

\author{
2018 \\ VOL. 3, NÚM. 1, SUPLEMENTO RESÚMENES
}

II JORNADAS ARGENTINAS DE ARACNOLOGÍA

(19 al 21 de septiembre, La Plata)

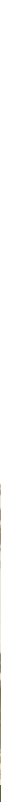




\section{Jornadas Argentinas de ARACNOLOGía}

\section{LIBRO DE RESÚMENES}

19 AL 21 DE SEPTIEMBRE DE 2018

CCT CONICET La Plata 


\title{
COMISIÓN ORGANIZADORA
}

\author{
Alda González \\ Mónica Cunningham \\ Fernando García \\ Aldana Laino \\ Sergio Rodríguez Gil \\ Sofía Romero \\ Cecilia Gabellone \\ Andrea Armendano \\ Sandra González \\ Guillermo Reboredo \\ Luis Giambelluca \\ Colaboradores \\ Pablo Addamo \\ Flavia Cassinelli \\ Nicolás Lischetti \\ Kevin Pons \\ Francisco Giambelluca \\ Carolina Abril Casanovas \\ Matías Bianco
}

\section{AUSPICIAN}
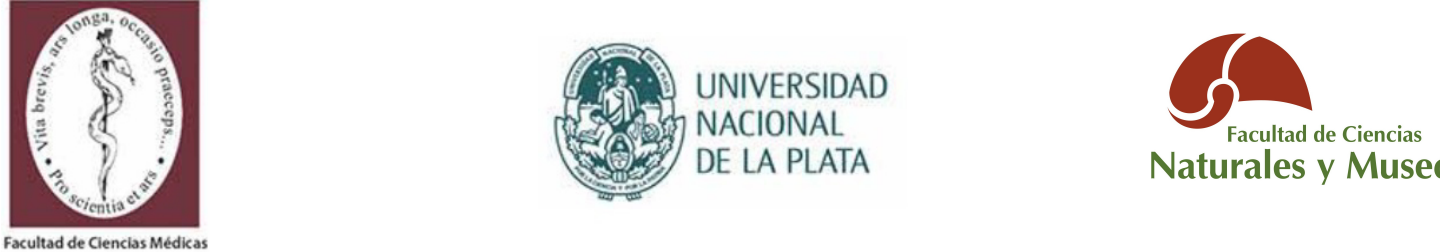

Naturales y Museo
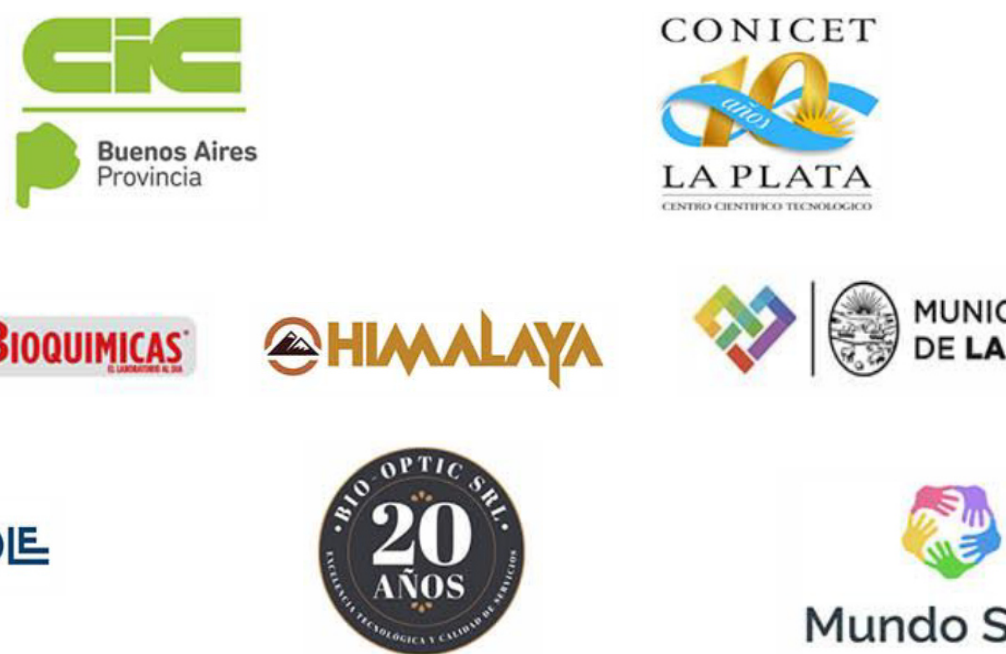

Mundo Sano 


\title{
CONFERENCIAS
}

\section{Biología evolutiva y diversidad de arañas: una visión global desde el sur}

\author{
Martín J. Ramírez \\ Museo Argentino de Ciencias Naturales “Bernardino Rivadavia”-CONICET ramirez@macn.gov.ar
}

¿Cómo es investigar la evolución de las arañas desde Argentina? A pesar de ser un país periférico, contamos con una excelente tradición y buena infraestructura para estudios de sistemática y biología comparada de arácnidos. Aún con preguntas de interés general, la ubicación geográfica desde donde se hacen los estudios influye en el tipo de preguntas y enfoques que se abordan. Desde el cono sur de Sudamérica tenemos acceso a una diversidad muy peculiar de especies, que atestiguan dinámicas evolutivas muy especiales: ciertos eventos geoclimáticos y escalas temporales, adaptaciones a ambientes específicos, origen de comportamientos novedosos e interacciones biológicas únicas. En esta presentación trataré de mostrar cómo nuestros estudios de biología evolutiva pueden tener un enfoque distintivo y original.

\section{Arañas como indicadoras ecológicas: sus respuestas a los disturbios antropogénicos}

\author{
José A. Corronca
}

Consejo Nacional de Investigaciones Científicas y Técnicas (CCT-Salta). Instituto para el Estudio de la Biodiversidad de Invertebrados (IEBI). Facultad de Ciencias Naturales, Universidad Nacional de Salta, Argentina. jcorronca@gmail.com

Las arañas responden rápidamente a los cambios en las condiciones ambientales debido a su gran dependencia al hábitat, por ello son consideradas buenos indicadores ecológicos. Los disturbios antropogénicos producen cambios en las condiciones y los recursos de los ambientes nativos lo que puede resultar en diferentes tipos de respuesta por parte de los organismos. Así, ante los disturbios, generalmente, puede ocurrir que la riqueza de especies y/o la abundancia no sufran cambios o se registre un decremento o incremento de ellas. Independientemente de la respuesta obtenida, es muy común que los ensamblajes de arañas de las comunidades nativas se modifiquen en los ambientes antropizados, en muchos casos siendo colonizadas por especies 
generalistas y, en otros, producto del desplazamiento y/o reemplazo de especies nativas típicas de esos ambientes. Estos cambios en los ensamblajes van acompañados, en gran medida, por los alteraciones en la heterogeneidad del hábitat y/o su recuperación. Desde hace varios años, el IEBI viene desarrollando diferentes proyectos en el noroeste de Argentina considerando los cambios en las comunidades nativas de arañas, y de otros artrópodos, como consecuencia de diferentes disturbios antropogénicos. Así, se evalúan las modificaciones ambientales producto de la explotación petrolera, el avance de la urbanización, la agricultura y la ganadería, como así también el aprovechamiento forestal y los incendios en ambientes nativos principalmente de Yungas y Chaco Serrano. Los muestreos siguen un protocolo de métodos de recolección estandarizados y complementarios. Se mostrarán los principales resultados obtenidos hasta la fecha en los diferentes proyectos, como así también se discutirá la importancia de contar con estrategias para realizar evaluaciones rápidas de la biodiversidad de arañas sobre la base de la suficiencia taxonómica. Éstas últimas permiten monitorear los cambios ambientales en el tiempo y dar soluciones a los organismos encargados de la toma de decisiones tendientes a la conservación de los ambientes nativos.

\title{
Comportamiento de arañas. Comunicación química entre arañas madre e hija. Aspectos subsociales
}

\author{
Marie Trabalon \\ Profesor de la Universidad de Rennes 1. (Area Neuroscience) Francia. \\ Miembro de la Sociedad Francesa para el estudio del Comportamiento Animal y de la Sociedad Europea de Aracnología \\ Marie.Trabalon@univ-rennes1.fr
}

La transición de la vida solitaria a la vida social durante la filogenia sigue siendo un enigma, incluso entre los insectos sociales (abejas, termitas, hormigas). Este pasaje está marcado por la aparición de determinados parámetros en los compuestos químicos presentes en la cutícula de los individuos y descriptos para algunas arañas. Estos compuestos interactúan determinando en parte el comportamiento de los padres, la cooperación en el cuidado de los jóvenes, la especialización de tareas y la aparición de individuos especializados en la reproducción. Los mecanismos para la supervivencia de los juveniles a menudo implica la coexistencia de tres categorías distintas de relaciones sociales. En primer lugar, las relaciones asimétricas entre la madre y el ámbito de aplicación; en segundo lugar, las relaciones simétricas entre los jóvenes dentro del ámbito de aplicación y en tercer lugar la relación temporal "madre joven". El comportamiento de tolerancia es la condición "sine qua non" para la supervivencia de la especie. 


\title{
Aspectos peculiares del comportamiento sexual en arañas subsociales
}

\author{
Carmen Viera \\ Entomología, Facultad de Ciencias, Universidad de la República, Montevideo, Uruguay \\ Ecología del Comportamiento, Instituto de Investigaciones Biológicas Clemente Estable, Montevideo, \\ Uruguay. cviera@fcien.edu.uy
}

Las arañas subsociales presentan algunas limitaciones para alcanzar un tipo de organización social más compleja. Una de estas limitaciones es la intolerancia entre hembras adultas, que imposibilita la cooperación en la captura de presas y el cuidado de la prole. En ese contexto, encontramos que el comportamiento sexual presenta algunas características peculiares. Los individuos abandonan el nido materno al alcanzar la adultez, pero las mudas son asincrónicas. Los machos adultos encuentran nidos ocupados por diferentes estadios de hembras y otros juveniles (nidos multi-hembras) o una sóla hembra (nidos uni-hembra). Antes de abandonar el nido, las hembras subadultas alimentan suplementariamente, mediante regurgitación, a sus hermanos (reconocimiento de parentesco) que alcanzan la madurez precozmente y abandonan el nido, evitando la endogamia. Los machos sobrealimentados presentan un desarrollo alométrico del primer par de patas que utilizan en los comportamientos antagónicos por el acceso a las hembras. Los machos vencedores de las contiendas, copulan primero con las hembras y el macho perdedor, permanece como satélite, siendo aceptado posteriormente. Los machos realizan guardia pre y post-copulatoria de las hembras. Las hembras subadultas son atractivas para los machos, adoptando una postura similar a la de las hembras adultas, aceptando la cópula. Los machos que seudocopulan con ellas, obteniendo algunos beneficios en el momento de poder copular. Las cópulas carecen de estrategias presentes en las arañas solitarias para inhibir la agresión de las hembras. Las estrategias sexuales de machos y hembras dependen del contexto social en el que se encuentren y por ello, analizamos cópulas en nidos uni-hembras y en nidos multihembras. 


\title{
SIMPOSIOS
}

\author{
Biogeografía y Conservación de Arácnidos en Argentina
}

COORDINADOR

NELSON FERRETTI

\section{Áreas de endemismo de arañas Mygalomorphae de Argentina y su importancia en la biogeografía de la conservación}

\author{
Nelson Ferretti ${ }^{1}$, Mariana Mancini $^{2}$ \\ ${ }^{1}$ Instituto de Ciencias Biológicas y Biomédicas del Sur (CONICET-UNS). Bahía Blanca, Buenos Aires, Argentina. \\ ${ }^{2}$ Departamento de Biología, Bioquímica y Farmacia, Universidad Nacional del Sur. Bahía Blanca, Buenos Aires, Argentina. \\ nferretti@conicet.gov.ar
}

Diversas entidades que trabajan en estrategias de conservación utilizan entre sus prioridades de conservación el criterio de áreas de endemismo (AE). Las AE son fundamentales en la biogeografía de la conservación porque si los sistemas de áreas protegidas las incluyen, se asegura la protección de áreas con importancia evolutiva y con elevada biodiversidad a nivel regional y global. Las arañas Mygalomorphae constituyen un grupo importante para estudios biogeográficos debido a sus limitados mecanismos de dispersión y alta endemicidad, por lo que se observa coincidencias en la distribución de algunas especies. De esta manera, tales patrones pueden ser analizados, por ejemplo mediante la identificación de AE. El objetivo del presente estudio fue identificar las AE para arañas Mygalomorphae de Argentina, mediante el método de optimación. Para ello se utilizaron registros de distribución de 104 especies y se usaron cuadrículas de $1^{\circ} \times 1^{\circ}$ y $0,5^{\circ} \times 0,5^{\circ}$ latitud-longitud. Se identificaron 5 áreas consenso diagnosticadas por 40 especies para cuadrícula de $1^{\circ}$. Las áreas con valor más alto de índice de endemicidad son, el Bosque Paranaense + Araucaria $(5,06,7$ especies), Yungas + Monte + Puna $\left(4,92,10\right.$ especies) y Comechingones $\left(4,08,4\right.$ especies). Utilizando una cuadrícula de $0,5^{\circ}$ se identificaron 5 áreas consenso soportadas por 23 especies. Las áreas con valor más alto de índice de endemicidad resultaron, el Bosque Paranaense + Araucaria (3,45, 4 especies), Yungas + Monte + Puna (3,13, 7 especies), Comechingones (2,99, 4 especies) y Ventania + Tandilia (2,73, 3 especies). Estos resultados muestran la importancia de áreas particulares en cuanto a endemismos y reflejan su compleja historia biogeográfica. Además, se comentan las áreas obtenidas en relación a las áreas protegidas existentes en nuestro país, con el fin de contribuir a la preservación de las mismas. 


\title{
El aporte de los arácnidos en la definición de áreas de endemismo en la Cuenca del Plata
}

\author{
Elián L. Guerrero, María J. Apodaca, Liliana Katinas \\ División Plantas Vasculares. Museo de La Plata. Facultad de Ciencias Naturales y Museo, Universidad Nacional de La Plata. Paseo \\ del Bosque s/n. 1900, La Plata, Argentina. CONICET. eguerrero@fcnym.unlp.edu.ar; apodaca@fcnym.unlp.edu.ar; \\ katinas@fcnym.unlp.edu.ar
}

\begin{abstract}
Algunas regionalizaciones biogeográficas de América del Sur destacan a la parte baja de la Cuenca del Plata (BCP) como una unidad distintiva por su fauna o sus comunidades vegetales. Entre ellas se destaca el esquema de áreas opilionológicas, que reconoce el Área Mesopotámica sensu stricto. Con el objetivo de establecer si la BCP puede ser considerada como una unidad biogeográfica, se realizó una búsqueda de áreas de endemismo. Se compendiaron los animales y plantas endémicos del área, se descartaron las que habitan pastizales y bosques xerófilos en terrenos topográficamente elevados y se seleccionaron 87 taxa cuya distribución se restringe a los humedales del sistema. Entre estos se contó con 14 especies de arácnidos de los órdenes Opiliones y Araneae. Combinamos los registros georeferenciados con observaciones de campo y datos de labelos de colecciones y literatura para estimar las áreas de distribución. Estas áreas de distribución fueron superpuestas para evaluar la simpatría entre ellas e identificar áreas de endemismo. Se halló un área de endemismo que comprende gran parte de la BCP e incluye tres sub-áreas: la primera, abarca el macrosistema de humedales de Iberá y los ríos Paraguay inferior y Paraná medio e inferior; la segunda comprende el sector medio del Río Uruguay y sus tributarios; y la tercera abarca el Delta del Paraná y el Río de la Plata. Se destacan algunas especies de opiliones como Hernandaria scabricula y Pucrolia minuta que diagnostican al BCP. Se discute la dificultad de identificar áreas de endemismo de pequeña extensión areal con los métodos biogeográficos que utilizan cuadrículas.
\end{abstract}

\section{Filogenia y evolución del nicho ambiental en las arañas de arena neotropicales (Sicariidae: Sicarius)}

\author{
Iván L.F. Magalhaes ${ }^{1}$, Danilo M. Neves ${ }^{2}$, Fabrício R. Santo ${ }^{3}$, Teofânia H.D.A. Vidigal ${ }^{3}$, Antonio D. \\ Brescovit $^{4}$, Adalberto J. Santos ${ }^{3}$

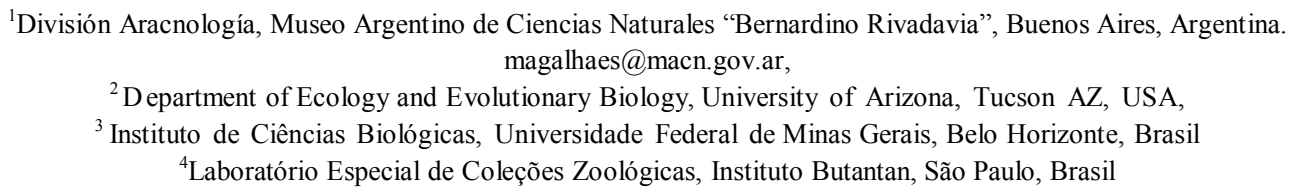


La conservación filogenética de biomas (CFB) limita la distribución de los organismos a condiciones climáticas particulares. Por otro lado, si áreas con climas similares están geográficamente aisladas, la diversificación también puede limitarse por las capacidades dispersivas. Los hábitats xerófilos neotropicales proporcionan un sistema ideal para evaluar los roles relativos del clima y la geografía en la diversificación, ya que ocurren en áreas disjuntas con biotas similares. Las arañas Sicariinae están íntimamente asociadas a estos ambientes xéricos, principalmente bosques tropicales secos (BTS) y desiertos/matorrales subtropicales. Obtuvimos una filogenia de Sicariinae y sus tiempos de divergencia usando datos morfológicos y de secuencias. Estimamos los nichos climáticos a partir de registros taxonómicos publicados. Usamos la filogenia para estimar nichos ancestrales y cambios entre biomas. Utilizamos métodos de partición de variación para probar la importancia relativa del clima y la geografía para explicar la variación espacial en la estructura filogenética de Sicarius. Los Sicarius neotropicales son antiguos y se separaron de su grupo hermano africano hace aproximadamente 90-110 millones de años. Los hábitats ancestrales de Sicariinae son desiertos, con 3-4 cambios a BTS. La mayor parte de la variación en la estructura filogenética se explica por la limitación de la dispersión que es independiente de las condiciones climáticas medidas. Los Sicariinae tienen una antigua asociación con las tierras áridas, lo que sugiere que el CFB les impidió colonizar los hábitats húmedos. Sin embargo, los nichos son lábiles en una escala más pequeña, con varios cambios de desiertos a BTS. Esto sugiere que CFB y la limitación de la dispersión a larga distancia jugaron un papel importante en el confinamiento de linajes a áreas aisladas de BTS/desierto a lo largo de la historia evolutiva, aunque los cambios entre los biomas xéricos ocurrieron siempre que se presentaron oportunidades geográficas.

\title{
Los escorpiones como indicadores para plantear estrategias de conservación ambiental, y comentarios sobre la primera especie protegida de escorpión en el Cono Sur
}

\author{
Andrés A. Ojanguren Affilastro \\ División Aracnología, Museo Argentino de Ciencias Naturales "Bernardino Rivadavia". Avenida Ángel Gallardo 470, CP 1405 \\ DJR. Ciudad Autónoma de Buenos Aires, Argentina. andres.ojanguren@gmail.com \& ojanguren@macn.gov.ar
}

El uso de artrópodos como indicadores para plantear estrategias de conservación ambiental está aún poco extendido; sin embargo, algunos grupos con una alta fidelidad al tipo de ambiente en el que habitan presentan un gran potencial para esto. La relativamente baja diversidad del orden escorpiones, junto con una alta abundancia local, y una taxonomía, en general, bien resuelta, los hacen un excelente modelo para proponer zonas y estrategias de conservación en áreas vulnerables; sin embargo, es necesario un profundo conocimiento de la sistemática del grupo en el área de estudio para respaldar estos trabajos. En el sur de Sudamérica existen tres familias de escorpiones, Bothriuridae, Buthidae y Caraboctonidae. 
Entre las dos primeras existen varias especies altamente ligadas a un tipo de ambiente determinado, que son además muy sensibles a cualquier cambio en las condiciones ambientales. $\mathrm{n}$ ejemplo de esto son las especies adaptadas a un tipo de ambiente en particular, como las ultrapsammófilas, que sólo pueden sobrevivir en ambientes dunarios, con sustrato de arena. Recientemente hemos propuesto como especie protegida a Brachistosternus cepedai, una especie ultra-psammófila, endémica de un pequeño sector de dunas costeras de la región de Atacama, en el norte de Chile. Esta fue declarada como especie en peligro para la legislación Chilena en el año 2017, debido a la alta presión antrópica que sufre el área en la que habita. Esta especie es sólo uno de varios endemismos de la zona, por lo que además, en una publicación reciente, sugerimos que se genere un área protegida en el área que ocupa. En esta contribución sugerimos la factibilidad del uso de los escorpiones como indicadores de áreas vulnerables, discutimos el caso de $B$. cepedai dentro del marco de nuestro trabajo en la sistemática del grupo, y planteamos varios casos de especies amenazadas en áreas vulnerables de la Argentina.

\title{
Ecología térmica de una especie de tarántula en riesgo de extinción (Grammostola vachoni): un enfoque a nivel individual y poblacional bajo un contexto de cambio climático global
}

\author{
Leonela Schwerdt ${ }^{1}$, Ana E. de Villalobos ${ }^{1}$, Nelson Ferretti ${ }^{2}$ \\ ${ }^{1}$ Centro de Recursos Renovables de la Zona Semiárida (CERZOS-CONICET); Departamento de Biología, Bioquímica y Farmacia, \\ Universidad Nacional del Sur. avillalo@criba.edu.ar, schwerdt@cerzos-conicet.gob.ar \\ ${ }^{2}$ Instituto de Ciencias Biológicas y Biomédicas del Sur (CONICET-UNS), Argentina.nferretti@conicet.gov.ar
}

Los procesos biológicos de los individuos son dependientes de la temperatura corporal, y en el caso de los individuos ectotermos dicha temperatura depende de forma directa o indirecta de la temperatura ambiental. Asimismo, la temperatura corporal tiene efectos importantes sobre el fitness de las especies ectotérmicas. En el caso de las arañas, se considera que la temperatura es uno de los parámetros principales ya que influye en la duración de los periodos de actividad, y en consecuencia puede tener un impacto importante en el comportamiento y en la ecología de los individuos. Las investigaciones sobre el efecto de las temperaturas en los procesos biológicos han sido enfocadas bajo un contexto del cambio climático global por lo que una reevaluación de las respuestas biológicas a las temperaturas extremas ha tenido lugar con el fin de determinar la variación potencial de diversos factores como la fenología, distribución geográfica, y la diversidad de las especies entre otros. A través de las Curvas de Rendimiento Térmico (CRT) es posible describir la tolerancia térmica y los efectos de la temperatura en procesos bioquímicos, fisiológicos o comportamentales. Los resultados se pueden aplicar para predecir las respuestas de las especies, poblaciones o comunidades en relación a los efectos de cambio climático global. Grammostola vachoni es una tarántula categorizada como vulnerable (UICN) que se encuentra únicamente en áreas montañosas y pastizales serranos del centro de 
Argentina. Se exponen los experimentos realizados en laboratorio con dicha especie y los resultados obtenidos, que permiten conocer las preferencias térmicas y estimar cómo influye la temperatura sobre el fitness de la especie. La evaluación de la tolerancia térmica es relevante por la adquisición de conocimientos acerca de la fisiología térmica y por la necesitad actual de comprender en qué medida los diferentes fenómenos térmicos como el cambio climático global afectan los parámetros biológicos de los individuos.

\title{
SELECCIÓN SEXUAL EN ARÁCNIDOS: UNA REVISIÓN DE LOS ROLES SEXUALES DESDE UNA PERSPECTIVA FEMENINA
}

\section{Inmovilidad de la hembra durante la cópula: es un fenómeno similar en los diferentes grupos de arañas?}

\author{
Débora A. Abregú, Camilo I. Mattoni, Alfredo V. Peretti
}

\begin{abstract}
Laboratorio de Biología Reproductiva y Evolución, Instituto de Diversidad y Ecología Animal (IDEA, CONICET-UNC), Facultad de Ciencias Exactas Físicas y Naturales, Universidad Nacional de Córdoba. debo_abregu@yahoo.com.ar, camilomattoni@gmail.com, aperettibec@gmail.com
\end{abstract}

Dentro del marco de selección sexual, se ha indagado sobre comportamientos del macho durante la cópula y como podrían influir en la elección post-copulatoria de la hembra (elección críptica), así como en competencia espermática. A su vez, las hembras también pueden generar señales durante la cópula como forma de comunicación con el macho. En particular, el comportamiento copulatorio femenino podría proporcionar señales internas importantes durante el apareamiento informando al macho sobre la transferencia de esperma o modulando comportamientos del mismo. Sin embargo, pese a que ha sido observado en varios grupos de arañas, hay escasos trabajos que han hecho énfasis en el rol aparentemente pasivo de la hembra durante la cópula. El fenómeno de quiescencia o catalepsia se caracteriza por ser un estado inmóvil de la hembra presente principalmente durante y después del apareamiento. Se ha sugerido que esto puede ser resultado de señales vibratorias, químicas y/o táctiles realizadas por el macho, y podría impedir ser atacado por la hembra y ayudar a una mejor transferencia espermática. También se ha sugerido que aún en estado cataléptico la hembra jugaría un rol funcional activo debido a que puede estar monitoreando la performance del macho y que inclusive mecanismos como la elección críptica podrían estar operando. En el presente trabajo se expondrá una revisión de los diferentes grados de catalepsia en distintos grupos de arañas, 
haciendo énfasis en el género Metaltella, familia Desidae. Este trabajo servirá de base para futuros estudios orientados a determinar la importancia de este comportamiento en el marco de la selección sexual.

\title{
Tácticas alternativas en hembras audaces y machos constructores
}

\author{
Fedra Bollatti ${ }^{1}$, Alfredo V. Peretti ${ }^{1}$, Anita Aisenberg ${ }^{2}$ \\ ${ }^{1}$ Laboratorio de Biología Reproductiva y Evolución, Cátedra de Diversidad Animal I, FCEFyN-UNC, Instituto de Diversidad y \\ Ecología Animal, CONICET-UNC, Argentina. fedrabollatti@gmail.com, aperettibec@gmail.com, \\ ${ }^{2}$ Departamento de Ecología y Biología Evolutiva, IIBCE, Montevideo, Uruguay. anita.aisenberg@gmail.com
}

Allocosa senex es una araña lobo nocturna que vive en playas arenosas de Argentina, Brasil y Uruguay. Esta especie presenta inversión de roles sexuales y de dimorfismo sexual de tamaño, esto significa que, a diferencia de los esperado para este grupo, las hembras son las encargadas de buscar pareja e iniciar el cortejo, siendo a su vez más pequeñas que los machos. Los machos construyen cuevas largas y permanecen dentro de éstas esperando las visitas femeninas, para donárselas una vez finalizado el apareamiento. Las hembras quedarán en su interior en donde realizarán su puesta de huevos para emerger una vez que las crías estén listas para la dispersión, por lo que se las consideraba como monándricas temporales. Sin embargo, no puede descartarse que estas hembras sean visitadas por otros machos, pudiendo llegar a copular con ellos. Para evaluar esta posibilidad, se realizaron encuentros sexuales entre individuos colectados en las localidades de La Bolsa y Nono, Córdoba $(n=15)$. Cada experiencia comenzó cuando la hembra fue introducida en un terrario con un macho en su cueva. Una vez ocurrida la cópula, se dejó permanecer 2-3 días a la hembra dentro de la cueva donada por el macho y se introdujo un segundo macho al terrario. Se registraron los comportamientos de ambos sexos. Resultados preliminares muestran que los machos son capaces de detectar y cortejar a hembras apareadas en cuevas donadas por otros machos (46,7\%), mientras que un $27 \%$ de las hembras responden al cortejo y un $20 \%$ incluso acepta el segundo apareamiento. Estos resultados sugieren que tanto hembras como machos de esta especie podrían adoptar tácticas reproductivas alternativas para aumentar sus respectivas tasas de apareamiento. 


\title{
Elección mutua de pareja: qué evalúan durante el cortejo los machos y hembras de un escorpión poligámico?
}

\author{
Mariela Oviedo-Diego ${ }^{1,2}$, David E. Vrech ${ }^{1,2,3}$, Paola A. Olivero ${ }^{1,2}$, Camilo I. Mattoni, ${ }^{1,2}$, Alfredo \\ V. Peretti ${ }^{1,2,3}$ \\ ${ }^{1}$ Universidad Nacional de Córdoba, Facultad de Ciencias Exactas, Físicas y Naturales, Departamento de Diversidad Biológica y \\ Ecología, Córdoba, Argentina. \\ ${ }^{2}$ Consejo Nacional de Investigaciones Científicas y Técnicas (CONICET), Instituto de Diversidad y Ecología Animal \\ (IDEA), Laboratorio de Biología Reproductiva y Evolución, Córdoba, Argentina. \\ ${ }^{3}$ Cátedra de Diversidad Biológica II. marie27oviedo@gmail.com; dvrech@gmail.com; paoolivero@gmail.com; \\ camilomattoni@gmail.com; aperettibec@gmail.com
}

Clásicamente se considera que las hembras son el sexo que elige y que los machos maximizan su éxito reproductivo adquiriendo múltiples parejas. Sin embargo, se conocen ejemplos de 'elección masculina' donde los machos invierten más (tanto a nivel precopulatorio como post-copulatorio) en hembras con ciertas características indicadoras de calidad. También se han encontrado especies donde la elección múltiple es adaptativa, en general cuando ambos sexos varían en calidad. Dentro de los arácnidos, el escorpión Bothriurus bonariensis (Bothriuridae) presenta un sistema de apareamiento poligámico y se conocen aspectos reproductivos y de elección femenina en esta especie. Mediante este trabajo nos proponemos evaluar si en este modelo existe elección múltiple y de qué variables depende el éxito de aceptación para el apareamiento en cada uno de los sexos. Se expusieron machos a hembras vírgenes cada diez días y se observó la aceptación de ambos sexos, luego se relacionó esta aceptación con la de condición corporal de los individuos y el número de exposiciones. Se colectaron los espermatóforos antes de la transferencia espermática por lo que se obtuvieron características del eyaculado para evaluar la inversión másculina post-copulatoria. Se encontró que la condición corporal de la pareja es evaluada tanto por machos como por hembras. Los machos más livianos y chicos son rechazados por las hembras mayor número de veces que machos de mejor condición. Los machos en general estuvieron siempre atraídos a las hembras pero presentaron variabilidad en características del eyaculado y comportamientos del cortejo según la condición corporal de ésta. El número de exposiciones también parece afectar el fenómeno de elección presentando interesantes patrones que se discutirán a fin de comprender de manera más acabada el sistema de apareamiento y la dinámica reproductiva de esta especie. 


\title{
¿Consentidas o astutas? La difícil elección de las hembras entre dos tácticas de apareamiento en arañas con regalo nupcial
}

\author{
Camila Pavón-Peláez ${ }^{1}$, Valentina Franco-Trecu ${ }^{2}$, María J. Albo ${ }^{3}$ \\ ${ }^{1}$ Laboratorio de Etología, Ecología y Evolución (LEEE), Instituto de Investigaciones Biológicas Clemente Estable (IIBCE), \\ Montevideo, Uruguay, cpavonpelaez@gmail.com. \\ ${ }^{2}$ Departamento de Ecología y Evolución, Facultad de Ciencias, UdelaR, Montevideo, Uruguay, vfranco- trecu@fcien.edu.uy. \\ ${ }^{3}$ Laboratorio de Etología, Ecología y Evolución (LEEE), Instituto de Investigaciones Biológicas Clemente Estable (IIBCE), \\ Montevideo, Uruguay, mjalbograna@gmail.com
}

Los machos de la araña neotropical Paratrechalea ornata pueden ofrecer regalos nupciales nutritivos (presa fresca) o simbólicos (restos no nutritivos). Las hembras raramente aceptan cópulas cuando el macho no ofrece regalo y frecuentemente rechazan los regalos no envueltos en seda. El regalo nutritivo beneficia a las hembras en términos de fecundidad. Sin embargo, al aceptar generalmente regalos envueltos en seda, las hembras no discriminan entre ambos, aceptando con igual frecuencia y duración la cópula. Se ha sugerido que las hembras podrían sesgar crípticamente el número de espermatozoides almacenados según el tipo de regalo. En este trabajo estudiamos si las hembras pueden evaluar el contenido del regalo a través de la honestidad del macho (consistencia en el ofrecimiento de regalos nutritivos) y su asociación con otros comportamientos durante el cortejo. Expusimos 18 machos con disponibilidad para producir un regalo nutritivo (presa) o simbólico (exosesqueleto) repetidamente a experiencias de cortejo frente a hembras. Encontramos alta flexibilidad en los machos, sin diferencias individuales en la táctica reproductiva. El hecho de que los machos sean plásticos dificultaría la evaluación de la hembra respecto al contenido del regalo del macho a través de comportamientos asociados. Analizamos la duración de la envoltura para cada tipo de regalo y la ocurrencia de ofrecimientos de regalos no envueltos. Los regalos simbólicos fueron envueltos por mayor tiempo que los nutritivos, y los machos de mayor tamaño ofrecieron mayor proporción de regalos simbólicos. De los machos que ofrecieron regalo simbólico, los de menor tamaño intentaron ofrecerlos sin envolver. Como consecuencia de los rechazos frente a los regalos no envueltos los machos iniciaron la envoltura. Esto sugiere un importante rol de las hembras en la producción del regalo y la envoltura en seda, siendo la cantidad de seda o capacidad de envolver y el tamaño posibles indicadores de calidad del macho.

\section{Lo que ellas quieren: efecto del comportamiento sexual femenino en el cortejo y cópula en Pachyloides thorellii (Opiliones, Gonyleptidae)}

\author{
Estefanía Stanley $^{1}$, Glauco Machado², Anita Aisenberg ${ }^{1}$ \\ ${ }^{1}$ Departamento de Ecología y Biología Evolutiva, Instituto de Investigaciones Clemente Estable, Montevideo, Uruguay. \\ estefaniastanley@gmail.com; anita.aisenberg@gmail.com. \\ ${ }^{2}$ Departamento de Ecología, Instituto de Biociencias, Universidad de San Pablo, San Pablo, Brasil. glaucoma@gmail.com
}


En especies poligámicas en las que las hembras tienen acceso a múltiples apareamientos, el esperma de dos o más machos puede coexistir dentro del tracto reproductivo femenino, permitiendo que la selección sexual opere no solo a través de los mecanismos precopulatorios de selección, sino además a través de mecanismos post-copulatorios como la competencia espermática y la elección críptica femenina. En estas especies se torna crucial estudiar el rol femenino en el contexto sexual para determinar qué rasgos comportamentales y/o morfológicos del macho son seleccionados. En este contexto, se espera que los machos presenten comportamientos y/o estructuras para atraer y estimular a las hembras, y que éstas presenten a su vez tanto comportamientos como estructuras que les permitan evaluar a los machos y solicitar una mayor estimulación o rechazarlos si es preciso. Los Opiliones presentan diversas características que los hacen buenos modelos para el estudio del rol femenino durante la cópula ya que las hembras participan activamente a lo largo del encuentro sexual. En esta presentación realizaremos una descripción detallada del comportamiento sexual de la especie Pachyloide thorellii en la cual encontramos evidencias principalmente comportamentales del posible rol femenino sobre el éxito reproductivo de los apareamientos en esta especie.

\title{
Sistemática, Diversidad y EVOLUCión de ARAÑaS
}

COORDINADOR

IVÁn MagalHaes

\section{Sistemática y Evolución de Arañas Gnaphosidae (Dionycha, Gnaphosoidea)}

\author{
Guilherme H. F. Azevedo ${ }^{1}$, Charles E. Griswold ${ }^{2}$, Adalberto J. Santos ${ }^{3}$ \\ ${ }^{1}$ División Aracnología, Museo Argentino de Ciencias Naturales "Bernardino Rivadavia". Av. Ángel Gallardo 470, C1405DJR, \\ Buenos Aires, Argentina. E- mail: ghfazevedo@gmail.com \\ ${ }^{2}$ California Academy of Sciences, 55 Music Concourse Drive, San Francisco, CA 94118, United States. \\ ${ }^{3}$ Departamento de Zoologia, Instituto de Ciências Biológicas, Universidade Federal de Minas Gerais. Av. Antônio Carlos, 6627, \\ 31270-901, Belo Horizonte, MG, Brasil.
}

Gnaphosidae es una familia de arañas muy diversificada y con interesante morfología de las hileras. Aunque el grupo ha recibido bastante atención taxonómica recientemente, sus relaciones filogenéticas siguen siendo desconocidas. En este trabajo, tratamos de desentrañar la historia evolutiva de la familia por medio de análisis filogenéticos. Una matriz con 324 caracteres morfológicos, observados en 71 géneros de gnafósidos y 29 terminales de grupos externos, fue analizada con métodos cladísticos y bayesianos. Gnaphosidae no fue recuperado 
como un grupo monofilético, ni la mayoría de las agrupaciones intrafamiliares previamente propuestas. De acuerdo con nuestros resultados, Vectius Simon y Hemicloea Thorell pertenecen a Trochanteriidae Karsch, y Xenoplectus Schiapelli \& Gerschman de Pikelin a Liocranidae. Micaria Westring, Nauhea Forster y Verita Ramírez y Grismado (y algunos géneros relacionados) posiblemente no son gnafósidos, aunque su posicionamiento filogenético es incierto. Gnaphosidae s.s. se definirá como un grupo monofilético de arañas con fúsulas de las glándulas piriformes más largas y más anchas que las fúsulas de las ampulaceas mayores. En el caso de Gnaphosidae s.s., clados bien soportados permiten la redefinición, con base filogenética cuantitativa, de Gnaphosinae Pocock, Zelotinae Platnick, Herpyllinae Platnick, Drassodinae Simon, y de una nueva subfamilia. Además, Prodidomidae Simon será redefinida como una subfamilia de Gnaphosidae. Muchos géneros no se asignaron a subfamilias debido a ubicaciones inestables y con poco soporte. La homología y la evolución de estructuras como el "clasper" del fascículo subungueal, las hileras y modificaciones en los quelíceros son discutidas. También se discute la evolución da la complejidad genital en este grupo de arañas.

\title{
Aportes de códigos de barra genéticos en la delimitación de especies para la subfamilia Amaurobioidinae
}

\author{
Mariana L. Barone, Martín J. Ramírez \\ División de Aracnología, Museo Argentino de Ciencias Naturales "Bernardino Rivadavia", Avenida Ángel Gallardo 470 \\ (C1405DJR), Ciudad Autónoma de Buenos Aires, Argentina. marianlbarone@gmail.com, ramirez@macn.gov.ar
}

En este trabajo se exploran los aportes de la técnica de códigos de barra genéticos (DNA barcodes) a la taxonomía de la subfamilia Amaurobioidinae. La técnica de barcoding genético utilizando el marcador Citocromo Oxidasa I (COI) ha probado ser de utilidad anteriormente en el caso de arañas, pero hasta el momento no se habían realizado estudios en cuanto a su eficacia en la delimitación de especies para esta subfamilia en particular. Se trabajó con ejemplares depositados en la colección del Museo Argentino de Ciencias Naturales (MACN), y préstamos ya recibidos procedentes de California Academy of Science (CAS); seleccionados de colectas en etanol 96\% para evitar muestras con posible degradación de material genético y también abarcando la mayor cantidad de especies de la subfamilia posibles y el área de distribución más amplia posible de cada una. Las secuencias del marcador COI se obtuvieron de acuerdo a los protocolos del Canadian Center of DNA Barcoding. En total se incluyeron 454 registros con representantes de los 22 géneros de la subfamilia Amaurobioidinae descriptos hasta el momento. Se obtuvo que de 88 especies determinadas morfológicamente, 71 encuentran correspondencia en la delimitación de Unidades Taxonómicas Operacionales sugerida por el sistema Refined Single Linkage implementado en la plataforma BOLD (Barcode of Life Data System). Los casos de disparidad entre estas delimitaciones corresponden tanto a una baja cantidad de registros representativos, como por otro lado posibles linajes divergentes. El análisis de este marcador además aporta información relevante al coincidir con observaciones 
de morfotipos diferentes dentro de una misma especie. Se concluye que la técnica de códigos de barra genéticos reafirma los límites de la mayoría de las especies determinadas por caracteres morfológicos de esta subfamilia y sienta las bases para el estudio más detallado de la delimitación morfológica en casos particulares.

\title{
Explorando la historia evolutiva de un taxón: revisión sistemática, Filogenia y Biogeografía del género sudamericano Petrichus (Araneae: Philodromidae)
}

\author{
Mariana Griotti ${ }^{1}$, Sergio Roig-Juñent ${ }^{1}$, Cristian Grismado ${ }^{2}$, Martín J. Ramírez ${ }^{2}$ \\ ${ }^{1}$ Instituto Argentino de Investigaciones de las Zonas Áridas (IADIZA, CCT-Mendoza), Argentina. mgriotti@mendoza- \\ conicet.gob.ar; saroig@mendoza-conicet.gov.ar \\ ${ }^{2}$ Museo Argentino de Ciencias Naturales Bernardino Rivadavia (MACN), Buenos Aires, Argentina. grismado@macn.gov.ar; \\ ramirez@macn.gov.ar.
}

La reconstrucción de la historia evolutiva de un taxón es posible de abordar bajo un enfoque multidisciplinar, siendo la Sistemática, el punto de partida en este abordaje. Los resultados de una revisión sistemática (particularmente de especies descriptas hace más de 100 años, cuyas descripciones son en su mayoría, de poco valor diagnóstico), constituyen la información de base para poner a prueba hipótesis filogenéticas y biogeográficas, e inferir sobre posibles escenarios evolutivos en el que un taxón se originó y diversificó. Un caso particular de descripciones ambiguas y material tipo difícil de rastrear, es el del género Petrichus. Estas arañas se distribuyen en los sistemas áridos y semiáridos de Sudamérica, tanto a lo largo de la cordillera de los Andes como en sistemas extra-andinos. Desde su publicación original, no existe un estudio taxonómico que corrobore la identificación de las especies circunscriptas al género tanto como sus relaciones de parentesco. Por ello, se realizó la revisión sistemática, Filogenia y Biogeografía del género sudamericano Petrichus Simon 1886 (Araneae: Philodromidae) a fin de reconstruir su historia evolutiva. La monofilia del género fue testeada en base a caracteres morfológicos y datos moleculares (COI, 16s, 28s, 18s, ITSII). Posteriormente, integrando árboles filogenéticos y datos de distribuciones (actuales y potenciales), se infirió sobre los posibles escenarios biogeográficos en los que Petrichus se diversificó en Sudamérica. Se definieron once especies (seis redescriptas y cinco nuevas), principalmente en base a la genitalia. Petrichus se recuperó monofilético en todas las estrategias de búsqueda. Finalmente, en base a su filogenia, se reconocieron varios patrones biogeográficos, y eventos de vicarianza y dispersión. Los resultados presentados aquí representan parte del trabajo de investigación en el marco de tesis doctoral. 


\title{
Análisis filogenético del género Orchestina (Araneae: Oonopidae) utilizando caracteres morfológicos y moleculares
}

\author{
Matías A. Izquierdo ${ }^{1}$, Martín J. Ramírez², Facundo M. Labarque ${ }^{3}$ \\ ${ }^{1}$ Laboratorio de Biología Reproductiva y Evolución, Instituto de Diversidad y Evolución Animal (UNC- CONICET), Córdoba, \\ Argentina.matias_iz@outlook.com \\ ${ }^{2}$ Museo Argentino de Ciencias Naturales "Bernardino Rivadavia" (MACN-CONICET), Ciudad \\ Autónoma de Buenos Aires, Argentina. ramirez@macn.gov.ar \\ ${ }^{3}$ Laboratório de Sistemática de Aracnídeos, Departamento de e Biologia Evolutiva (DEBE), Universidade Federal de São Carlos \\ (UFSCar), SP, Brazil. facundo.labarque@gmail.com
}

El género Orchestina pertenece a un grupo de arañas sumamente diverso y mundialmente distribuido. Se caracteriza por la presencia de fémures engrosados en el cuarto par de patas, lo cual les da la capacidad de dar pequeños saltos. En los últimos años se han descripto una gran cantidad de especies principalmente para África y América incrementando significativamente la diversidad del grupo. Datos provenientes de estudios morfológicos y filogenéticos indican que se trataría de un grupo monofilético, hermano de toda la familia, aunque las relaciones internas del género aún no han sido evaluadas. En este trabajo presentamos la filogenia de Orchestina basada en caracteres morfológicos y moleculares bajo diferentes aproximaciones utilizando representantes de América, África, Asia y Australia. Se discute la implicancia de valores de soportes bajo diferentes estrategias e hipótesis de agrupamientos, resaltando la importancia de algunos caracteres para el estudio evolutivo del grupo.

\section{La historia evolutiva de las arañas lobo}

\author{
Luis N. Piacentini, Martín J. Ramírez \\ Museo Argentino de Ciencias Naturales "Bernardino Rivadavia", Buenos Aires, Argentina. \\ luis.piacentini@gmail.com; ramirez@macn.gov.ar
}

Presentamos los resultados de dos proyectos en curso, uno dirigido a reconstruir las relaciones cladísticas de nivel superior en Lycosidae y su datado, y el otro a explorar la diversidad de la familia Lycosidae en Argentina mediante la utilización del BARCODE. Este trabajo es el primer análisis filogenético que incluye representantes de la totalidad de las subfamilias. Utilizamos marcadores moleculares mitocondriales (COI, NADH1 y 12S) y nucleares (28S, H3) de más de 70 especies de unos 60 géneros de la familia Lycosidae. Como grupos externos se utilizaron representantes de las familias Ctenidae, Oxyopidae, Pisauridae, Psechridae, Trechaleidae y Thomisidae. Para estimar los tiempos de divergencia se utilizaron 
dos fósiles, uno de Oxyopidae y otro de Thomisidae como punto de calibración y los valores de tasas de substitución nucleotídica publicadas. En la topología del árbol obtenido se recuperan en grupos monofiléticos a la mayoría de las subfamilias previamente publicadas, excepto por Piratinae y Lycosinae que se recuperan en grupos parafiléticos. Como resultado del análisis de datado se puede concluir que la familia Lycosidae tiene un origen reciente en la historia evolutiva de las arañas. Para evaluar la aplicación del BARCODE se obtuvieron más de 400 secuencias entre las cuales se encuentran representadas 41 de las 89 especies de Lycosidae descriptas para Argentina. Para evaluar las relaciones entre especies y los límites de las mismas se incorporaron los datos de COI a la filogenia de Lycosidae previamente mencionada y se analizaron los datos mediante inferencia bayesiana. La correspondencia entre los agrupamientos obtenidos y caracteres morfológicos está siendo evaluada, datos preliminares sugieren la presencia de 21 especies no descriptas, 12 nombres sinónimos y 13 géneros nuevos para América del Sur.

\title{
Evolución morfológica de las especies de arañas del género Philisca (Araneae, Anyphaenidae)
}

\author{
Eduardo M. Soto ${ }^{1}$, Pablo Milla Carmona ${ }^{2}$, Nicolás Mongiardino Koch $^{3}$, Sara \\ Ceccarelli ${ }^{4}$, Martín J. Ramírez ${ }^{5}$ \\ ${ }^{1}$ Laboratorio de Evolución, Departamento de Ecología, Genética y Evolución, IEGEBA (CONICET- UBA), \\ edusoto@ege.fcen.uba.ar \\ ${ }^{2}$ Departamento de Ciencias Geológicas, Instituto de Estudios Andinos "Don Pablo Groeber" (IDEAN, CONICET-UBA), \\ pablomillac@gmail.com \\ ${ }^{3}$ Department of Geology \& Geophysics, Yale University, USA, mongiar@hotmail.com \\ ${ }^{4}$ Departamento de Biología de la Conservación, Centro de Investigación Científica y de Educación Superior de Ensenada, México, \\ saracecca@hotmail.com \\ ${ }^{5}$ División de Aracnología, Museo Argentino de Ciencias Naturales “Bernardino Rivadavia”, ramirez@macn.gov.ar
}

Los archipiélagos oceánicos proveen de condiciones excepcionales para el estudio de patrones evolutivos, entre los que destaca el estudio de radiaciones adaptativas. Los nuevos nichos ecológicos disponibles en las islas volcánicas son ocupados gradualmente por las especies, resultando en endemismos locales. El género Philisca es endémico de la selva templada Valdiviana, ubicada a lo largo la cordillera de los Andes y el archipiélago Juan Fernández, (Chile), y está conformado por 14 especies de las cuales la mitad son endémicas de la isla. Hemos observado que a lo largo de su historia evolutiva, existió un único evento de colonización, seguido de un aumento en la tasa de especiación. Las especies isleñas parecerían mostrar mayores tamaños corporales como también la ocupación de diversos nichos ecológicos no observados en el continente. Nuestro objetivo es evaluar la evolución de los diferentes caracteres morfológicos en la historia evolutiva del género Philisca, y su asociación con la colonización de nuevos nichos. Analizamos el tamaño y la forma del cuerpo de las especies de Philisca. Utilizamos los paquetes phytool, phylolm y geiger en R, para evaluar el modelo morfológico evolutivo que mejor se ajusta a la evolución morfológica 
del género, y una filogenia molecular calibrada obtenida por un método de reconstrucción Bayesiano a partir de los genes COI, 16S, 28S y Histona3. Observamos que las especies del continente tienen morfologías diferentes a las isleñas. El tamaño corporal estaría evolucionando hacia un óptimo morfológico, evidenciando un proceso adaptativo. En cambio, los componentes de la forma corporal estarían indicando una diversificación morfológica asociada al uso de diferentes nichos por parte de las especies de Philisca. Por lo tanto, la evolución de la morfología corporal de las especies del género Philisca parecería evidenciar una compleja historia evolutiva dominada por el efecto de colonización de los nichos nuevos de una isla.

\section{Alergias, Clínica y Venenos}

COORDINADOR

SERGIO RODRÍGUEZ GIL

\section{Dr. Tomás Orduna}

Jefe del Servicio de Medicina del Viajero del Hospital e Enfermedades Infecciosas Francisco Javier Muñiz (Ciudad Autónoma de Buenos Aires)

\section{Dra. Susana C. Lloveras}

Infectóloga del Hospital de Enfermedades Infecciosas Francisco Javier Muñiz. (Ciudad Autónoma de Buenos Aires)

\section{Dra. María L. Yantorno}

Servicio de Infectologia. Hospital San Martín de La Plata (Provincia de Buenos Aires)

Se propondrá un intercambio distendido que aborde la clínica de casos de accidentes por arañas, escorpiones (con especial énfasis en aquellas especies cuyo veneno es de interés sanitario) y garrapatas. Se presentará el primer caso autóctono de Fiebre Manchada por Ricketsia parkeri (enfermedad transmitida por garrapatas) en Ensenada, provincia de Buenos Aires. Este caso motivó a una investigación, que concluyó en la redacción de una guía de manejo de Ricketsias y permitió encender un alerta en las sociedades médica y no médica.

Se pretende discutir la importancia de pensar, diagnosticar y notificar estos casos, pudiendo trabajar en forma conjunta médicos, veterinarios y biólogos para la toma de acciones de prevención y control. 


\title{
Primer Simposio Argentino de ACARología
}

\author{
COORDINADORES \\ Marisa Regonat, Claudia CÉDOla
}

\section{El potencial de los ácaros depredadores como agentes de control de plagas en agroecosistemas}

\begin{abstract}
Claudia V. Cédola
Centro de Estudios Parasitológicos y de Vectores (CONICET CCT La Plata, FCNyM-UNLP). Bulevard 120 entre 60 y 64 s/n 1900 La Plata, Argentina.ccedola@fcnym.unlp.edu.ar

En Argentina, el control de plagas agrícolas se realiza principalmente con productos químicos, que si bien reducen las poblaciones de las plagas temporalmente, generan resistencia y dependencia a los agroquímicos utilizados. Actualmente, hay una fuerte demanda social en producir alimentos sanos y de manera amigable con el ambiente y es ahí donde los organismos benéficos, entre ellos los ácaros depredadores, tienen importancia. Las familias más frecuentes halladas en los agroecosistemas, principalmente hortícolas, son Phytoseiidae, Erythraeidae, Anystidae, Laelapidae, Macrochelidae. Los ácaros Phytoseiidae han sido intensamente estudiados desde la década del 60' debido a su potencialidad como controladores biológicos de plagas asociadas a los cultivos hortícolas, frutales, cítricos, y ornamentales, tales como: ácaros, trips y moscas blancas. Los miembros de esta familia cosmopolita se encuentran principalmente sobre las plantas y utilizan también otros recursos como el polen, los exudados vegetales y las sustancias azucaradas que excretan algunos insectos. Junto a los Phytoseiidae, ácaros de la Fam. Erythraeidae, Balaustium sp. han demostrado ser valiosos agentes de control de plagas hortícolas principalmente en cultivos orgánicos en el cinturón hortícola platense. Muchas plagas, que realizan parte o todo el ciclo de desarrollo en el suelo, ocasionan pérdidas económicas importantes. Existen serios problemas con fitonematodes, moscas (Sciaridae y Muscidae) ácaros como Rhizoglyphus sp. que daña principalmente cultivos de ajo, cebolla y liliáceas y trips (que cumple una parte de su ciclo en el suelo). En el suelo podemos encontrar ácaros Pachylaelapidae y Parasitidae que depredan eficazmente sobre dichas plagas. El objetivo de este trabajo es dar a conocer algunos aspectos ecológicos de los ácaros depredadores (Phytoseiidae, Erytraeidae, Pachylaelapidae, y Parasitidae) como controladores de plagas de las plantas y del suelo. Se presenta información sobre ciclos de vida, capacidad de consumo y nicho trófico. La información recabada hasta el presente muestra la necesidad de continuar con la caracterización biológica de estos organismos benéficos.
\end{abstract}




\title{
Ácaros Mesostigmata de vida parásita. Sistemática, distribución e importancia sanitaria en la Argentina
}

\author{
Marcela Lareschi \\ Centro de Estudios Parasitológicos y de Vectores, CEPAVE (CONICET-UNLP) \\ mlareschi@cepave.edu.ar
}

Los mesostigmata constituyen un componente importante en la comunidad ectoparásita de reptiles, aves y mamíferos, que habitan sobre el cuerpo de los hospedadores, en sus nidos y madrigueras. Algunos son hematófagos obligados y otros se alimentan de líquidos tisulares y descamaciones de la piel. Son importantes como parásitos, vectores de patógenos (virus y bacterias) y hospedadores intermediarios (filarias), pudiendo provocar enfermedades a sus hospedadores y participar en el mantenimiento de las mismas entre animales silvestres, domésticos y el hombre. Además, en ausencia de sus hospedadores habituales, los mesostigmata pueden parasitar al hombre produciendo irritación y dermatitis alérgica. En la Argentina las familias Laelapidae y Macronyssidae son las más abundantes y diversas y se asocian principalmente a roedores silvestres. Sin embargo, solamente alrededor de 20 especies fueron identificadas, un número muy bajo si se compara con el de otros ectoparásitos como las pulgas, 130 especies. Esta diferencia en la riqueza específica sugiere que para los ácaros la misma estaría subestimada, posiblemente en relación a la presencia de especies crípticas que precisan de metodologías específicas para su identificación, y/o a la falta de relevamientos en determinadas áreas del país o en ciertos grupos hospedadores. En este sentido, relevamientos preliminares mostraron altas abundancias y prevalencias de mesostigmata en la región Neotropical y en roedores de las tribus Akodontini y Oryzomyini, mientras que estos parámetros disminuyeron considerablemente en la región Andina y en roedores de las tribus Phyllotini y Abrotrichinii. Estudios a una escala menor, en la costa bonaerense del Río de la Plata, mostraron que la distribución de algunas especies respondería al hospedador, otras al ambiente, y otras a ambos. Respecto de su importancia sanitaria, los resultados de estudios en mesostigmatas son preliminares.

\section{Ácaros oribátidos en Argentina: sistemática y distribución}

Pablo A. Martínez

Departamento de Biología, Facultad de Ciencias Exactas y Naturales, Universidad Nacional de Mar del Plata Funes 3350,7600
Mar del Plata. pamartin@mdp.edu.ar

En el presente trabajo se revisa la información actualizada de las especies de ácaros oribátidos citadas para Argentina y se caracterizan diversos ambientes en base a la presencia y abundancia de ellas. Para lograrlo se aplican los índices desarrollados por Aoki en base a las 
proporciones de especies de Macropylina (M), Brachypylina Gymnonota (G) y Brachypylina Poronota (P) (Aoki I) y de la abundancia de los mismos grupos (Aoki II). Se interpretan los patrones hallados utilizando criterios ecológicos y evolutivos. Asimismo, se analiza la composición a nivel de familias para comparar ambientes que tienen patrones similares. Entre otros resultados, a partir del índice basado en las proporciones de especies se observa un patrón de tipo $\mathrm{G}(\mathrm{G}>50 \%)$ para bosques subtropicales y templados y un considerable reemplazo de familias; un patrón tipo $\mathrm{P}(\mathrm{P}>50 \%)$ para bosques xerófilos del norte del país, compartido con algunos agroecosistemas bonaerenses; otros ambientes muestran dominancia de dos grupos (tipo GP), como los bosques de tala y de caldén, junto con algunos sistemas agrícolas y cerrilladas; finalmente los ambientes de monte y estepa patagónicos presentan una proporción pareja entre los grupos de oribátidos (tipo MGP). El índice basado en abundancia muestra asociaciones entre ambientes que no permiten una fácil interpretación. El estudio se basa en trabajos publicados y en muchos datos propios no publicados.

\title{
Paleobiología y filogenia de la familia Caeculidae (Acari Acariformes: Prostigmata)
}

\author{
Andrés Porta \\ Museo Museo Argentino de Ciencias Naturales "Bernardino Rivadavia"- Conicet. Angel Gallardo 490, C1405DJR CABA. \\ hugporta@yahoo.com.ar
}

En este trabajo se hace una revisión del registro paleontológico de la familia Caeculidae en base a la reexaminación de material de todas las especies fósiles descriptas. Se presentan, asimismo, nuevos hallazgos para la familia en materiales de ámbar cretácico y eocénico, se proponen hipótesis filogenéticas para los géneros Procaeculus Jacot, 1936; Neocaeculus Coineau, 1967 y Andocaeculus Coineau 1974, y para la familia Caeculidae se plantean dos hipótesis filogenéticas alternativas basadas en el análisis de caracteres morfológicos.

\section{Ácaros fitófagos: Sistemas de vigilancia, detección e identificación}

\author{
Marisa Regonat ${ }^{1,2}$ \\ ${ }^{1}$ Servicio Nacional de Sanidad y Calidad Agroalimentaria (Senasa). \\ ${ }^{2}$ Cátedra de Zoología Agrícola. Facultad de Agronomía. Universidad de Buenos Aires. mregonat@senasa.gob.ar
}


En la actualidad, el incremento de la comercialización internacional y el turismo, producto de la globalización, brindan a las plagas agrícolas las herramientas necesarias para maximizar su dispersión alrededor del mundo. Asimismo, este hecho se ve incrementado por las grandes migraciones de personas y los eventos climáticos que son capaces de llevar estos organismos a grandes distancias. En este marco, cobran relevancia los ácaros fitófagos, conocidos por el daño que generan a los cultivos producto de su actividad alimentaria, pero también porque muchos son tienen la capacidad de ser vectores de bacterias, virus y hongos, entre otros. Esto último, tiene un gran impacto para los cultivos afectados. Se estima que existen 60000 especies de ácaros descriptas y que unos 7500 son de importancia para la agricultura. Es por ello, que los países aplican las normativas internacionales de protección fitosanitaria a fin de minimizar el riesgo de introducción en su territorio, conocer la distribución local y establecer áreas libres de las plagas. Se plantea realizar una revisión de los casos emblemáticos más recientes para la agricultura nacional en el marco los sistemas de vigilancia implementados por Senasa en los últimos años, con énfasis en la detección e identificación.

\title{
Ponencias Orales
}

\author{
SiSTEMÁTICA
}

\section{Revisión taxonómica del género Neotrops Grismado \& Ramírez 2013 (Araneae: Oonopidae) parte II: la fauna de Brasil}

\author{
Cristian J. Grismado, Martín J. Ramírez \\ División Aracnología, Museo Argentino de Ciencias Naturales "Bernardino Rivadavia”, Buenos Aires, Argentina. \\ grismado@macn.gov.ar, ramirez@macn.gov.ar
}

El género Neotrops Grismado \& Ramírez, comprende hasta ahora 28 especies y tiene distribución neotropical, desde Panamá hasta Uruguay y centro de Argentina. Se caracteriza por su genitalia: los machos tienen una vesícula interna asociada al conductor del bulbo copulador y las hembras tienen un receptáculo anterior con función de almacenamiento de esperma y una placa esclerotizada posterodorsal en lugar del receptáculo posterior típico de la superfamilia Dysderoidea. Se propusieron cuatro grupos de especies en los cuales estarían englobadas la mayoría de las especies conocidas. En una primera etapa del estudio se abordaron las faunas de todos los países excepto Brasil, dado que la complejidad logística de trabajar con las grandes colecciones de ese país obligó a organizar el trabajo en dos partes. En esta segunda etapa del trabajo se abordó la fauna brasileña (mayormente sobre la base de las colecciones del Instituto 
Butantan y el Museo Emílio Goeldi) llegándose al reconocimiento y caracterización de 70 especies nuevas. Se diseñó una matriz morfológica con 86 caracteres preliminares. El grupo interno está compuesto por 23 terminales, representando los cuatro grupos de especies previamente propuestos, y siete que no estarían a priori incluidas en ninguno de los mismos. Como grupos externos se seleccionaron representantes de ocho géneros de Oonopidae (Gradunguloonops, Oonops, Birabenella, Heteroonops, Predatoroonops, Cinetomorpha, Neoxyphinus, Trilacuna, Puan y Orchestina); Orsolobidae, Dysderidae y Segestriidae. Hasta el momento se realizaron ensayos preliminares para el árbol filogenético en el que, aún con mucho trabajo pendiente, se recupera la monofilia del género y de uno de los grupos previamente propuestos (gr. nigromaculatus). Neotrops sería el género más diverso de Oonopinae neotropicales, estimándose en casi cien especies reconocidas. La mayor diversidad se registra en la mata atlántica brasileña y áreas circundantes, en los estados de Minas Gerais, Rio de Janeiro, Espirito Santo y São Paulo.

\title{
Los opiliones del género Stenostygnus en Venezuela (Opiliones: Laniatores: Biantidae)
}

\author{
Claudia V. Mamani, Willians Lourenço Porto, Patricia P. Iglesias, Abel \\ Pérez González
}

División de Aracnología, Museo Argentino de Ciencias Naturales "Bernardino Rivadavia", Buenos Aires, Argentina. lic988vane@gmail.com; w.insecta@gmail.com; patricia.p.iglesias@gmail.com; abelaracno@gmail.com

Stenostygninae Roewer, 1913, es una subfamilia (9 géneros y $18 \mathrm{spp}$.) endémica de la Región Neotropical de la cual solo hay descrita, hasta el presente, una sola especie: Stenostygnus pusio Simon, 1879. La primera cita de Biantidae para Venezuela fue realizada por Gonzalez-Sponga cuando publicó una clave dicotómica para las familias de opiliones de este país, sin embargo, ninguna especie en particular fue citada. En el V Congreso Latinoamericano de Aracnología, Minas Gerais, Brasil, informamos sobre la presencia de una nueva especie de este género (Stenostygnus sp. nov. 1) para Venezuela, todavía inédita. La presente contribución tiene como objetivo dar a conocer una segunda nueva especie (Stenostygnus sp. nov. 2) para este país. Stenostygnus sp. nov. 1 habita en el Estado de Lara y Stenostygnus sp. nov. 2 fue colectada en el Estado de Mérida (ambos lotes depositados en el MNRJ, Brasil). Las dos nuevas especies presentan características exomorfológicas muy parecidas a Stenostygnus pusio, con un habitus ovalado y áreas mesotergales/tergitos libres inermes. Además, los machos no poseen los característicos metatarsos III ensanchados presentes en los otros géneros (Antillanos) de Stenostygninae. Sin embargo, se separan de Stenostygnus pusio, por poseer una espina meso- medial en el fémur y una meso-distal en la patela del pedipalpo. Por otro lado, Stenostygnus sp. nov. 1 se diferencia del resto dado que los machos exhiben una fuerte apófisis espiniforme dorso-distal en la patela IV. Stenostygnus sp. nov. 2 se diferencia, por la presencia de quelíceros hipertélicos en machos y por poseer una hilera de tubérculos 
retrolaterales en la tibia IV. La genitalia masculina es diagnóstica para cada especie. Todas presentan una hendidura longitudinal en la región ventral de la pars distalis, sin embargo, su porción apical difiere entre las especies, al igual que la forma del estilo, los conductores y la distribución de las macrosetas.

\title{
Colección de arañas del Museo de Historia Natural de La Pampa
}

\author{
Nicolás Peralta Seen, César A. Stella \\ Museo de Historia Natural de La Pampa, La Pampa, Argentina. nicops23@hotmail.com; cesarstealla7@gmail.com
}

Las colecciones biológicas representan una herramienta fundamental para el estudio de la historia natural, taxonomía, conservación y distribución de los organismos. El Museo Provincial de Historia Natural cuenta con una colección aracnológica de más de 3500 ejemplares compuesta por arañas, escorpiones, pseudoescorpiones, ácaros y opiliones. En este trabajo se presenta la colección de arañas, la cual comenzó a formarse a principios del 1960, con ejemplares recopilados por Reinaldo O. Aravena y determinados por Rita D. Schiapelli y Berta Gerschman de Pikelín. Hasta el momento cuenta con 1150 ejemplares, 96\% colectados en La Pampa, distribuidos en 31 familias, 64 géneros y 55 especies. Se destacan a Pikelinia sp., Navira naguan, Alpaida rubellula y Catumiri argentinense, como nuevos registros para la provincia. A partir de 2017 la colección se encuentra en un proceso de restauración y reorganización que incluye la adhesión al Sistema Nacional de Datos Biológicos (SNDB) y al Global Biodiversity Information Facility (GBIF).

\section{Arañas Saltícidas de Misiones - Guía para la identificación (Tribus Basales)}

\author{
Gonzalo D. Rubio ${ }^{1}$, Julián E. Baigorria ${ }^{2}$, Cristina L. Scioscia $^{3}$ \\ ${ }^{1}$ CONICET; Estación Experimental Agropecuaria Cerro Azul (INTA). Cerro Azul, Misiones, Argentina. gonzalodrubio@gmail.com \\ ${ }^{2}$ Fundación de Historia Natural Félix de Azara. Ciudad Autónoma de Buenos Aires, Argentina. julianbaigorria@gmail.com \\ ${ }^{3}$ División Aracnología, Museo Argentino de Ciencias Naturales "Bernardino Rivadavia". Ciudad Autónoma de Buenos Aires, \\ Argentina.crisscio@yahoo.com.ar
}

Presentamos en esta guía el primer compendio sobre saltícidas de la Argentina, en especial de la provincia de Misiones, la más rica en diversidad de la familia. Este primer volumen de la guía comprende una compilación y tratado de especies de las tribus basales de la familia 
Salticidae. Es decir, hemos agrupado a las especies en tribus y éstas están, a su vez, organizadas según un orden evolutivo (sensu Maddison 2015). Las tribus que tratamos en este tomo son las primeras de dicho orden. La guía pretende además reunir la información disponible para ser utilizada en dos niveles: uno, como guía de identificación a campo (de bolsillo) de gran parte de las especies de Misiones, mediante fotografías tomadas de especímenes vivos, mayormente en su medio natural; y otro, para identificar a estas especies en el laboratorio mediante dibujos de sus caracteres diagnósticos. Es así, que los autores pretendemos que sea un elemento complementario de fácil acceso y manejo, no sólo para naturalistas y aficionados, sino también para jóvenes aracnólogos y especialistas en la materia. Salvo algunas excepciones, todas las imágenes fueron creadas por los autores. La mayoría de los dibujos fueron modificados/redibujados a partir de sus fuentes bibliográficas originales, muchos sobre la base de publicaciones de María E. Galiano y a quienes los autores reconocen la gran ayuda que han supuesto estos trabajos. La guía incluye una pequeña galería fotográfica de especies de las tribus que no se han tratado aquí y un listado completo de todas las especies de Salticidae registradas para la Argentina. De esta forma, y como línea base de especies, ésta es la $1^{\circ}$ edición y etapa de resultados; a partir de ahora la guía estará en permanente actualización cada vez que se descubran nuevas especies y registros; y continuaremos publicando, en nuevos tomos, los conocimientos del resto de las tribus que faltan incorporar.

\title{
ETOLOGÍA
}

\section{Caracterización del mecanismo de cópula en Agalenocosa pirity (Araneae: Lycosidae)}

\author{
Dante Poy $^{1}$, Martín J. Ramírez ${ }^{2}$, Peter Michalik ${ }^{3}$, Luis N. Piacentini ${ }^{4}$ \\ ${ }^{1}$ Museo Argentino de Ciencias Naturales "Bernardino Rivadavia”, Buenos Aires, Argentina, dante.poy@gmail.com; \\ ${ }^{2}$ Museo Argentino de Ciencias Naturales "Bernardino Rivadavia”, Buenos Aires, Argentina, ramirez@macn.gov.ar; \\ ${ }^{3}$ Universität Greifswald, Greifswald, Alemania, michalik@uni-greifswald.de; \\ ${ }^{4}$ Museo Argentino de Ciencias Naturales "Bernardino Rivadavia", Buenos Aires, Argentina, luis.piacentini@gmail.com
}

Agalenocosa pirity es una especie de araña lobo de tamaño medio perteneciente a la subfamilia Piratinae (Lycosidae). La misma presenta hábitos semiacuáticos, siendo frecuentemente hallada en orillas de lagunas y estanques de Corrientes, Entre Ríos y Buenos Aires. En este trabajo se planteó estudiar aspectos comportamentales del proceso de cópula de $A$. pirity y las interacciones mecánicas que acontecen entre las genitalias de ambos sexos. Para estudiar el comportamiento sexual de esta especie se realizaron filmaciones de cópulas bajo condiciones controladas de laboratorio, donde se evidenció la ausencia de un cortejo elaborado. Además, se relevaron variables de interés como duración de la cópula, número y tipo de 
inserciones palpales y número de eyaculaciones, las cuales fueron comparadas con datos bibliográficos de especies de licósidos emparentadas. Posteriormente se procedió a tomar mediciones somáticas de las parejas utilizadas a fin de establecer una posible relación entre estas variables y el comportamiento sexual de la especie en cuestión. Los resultados preliminares sugieren que la ausencia de cortejo observada en esta especie estaría relacionada a su reducido o nulo dimorfismo sexual en el tamaño. Para el estudio de interacción genital se fijaron parejas en cópula utilizando nitrógeno líquido. Luego, se tomaron imágenes de microscopía óptica y tomografías computadas de rayos $\mathrm{x}$ de las parejas fijadas. Se logró corroborar que la función de conducción del émbolo es llevada a cabo por el sinémbolo, y se observó una función de anclaje novedosa entre la palea y un bolsillo poco evidente localizado en la parte posterior del epigino. También, se tomaron medidas genitales a fin de establecer los rangos de variabilidad en el tamaño existentes e intentar comprender los procesos evolutivos que podrían haber modelado este tipo de morfología genital.

\title{
Desarrollo biológico y estudio de alometrías en Grammostola vachoni Schiapelli \& Gerschman, 1961 (Theraphosidae, Mygalomorphae)
}

\author{
Leonela Schwerdt ${ }^{1}$, Ana E. de Villalobos ${ }^{1}$, Fernando Pérez-Miles ${ }^{2}$ \\ ${ }^{1}$ Centro de Recursos Renovables de la Zona Semiárida CERZOS-CONICET, Departamento de Biología, Bioquímica y Farmacia, \\ Universidad Nacional del Sur, Bahía Blanca, Argentina.1schwerdt@cerzos-conicet.gob.ar; avillalo@criba.edu.ar \\ ${ }^{2}$ Sección Entomología, Facultad de Ciencias, Universidad de la República, Montevideo, Uruguay. myga@fcien.edu.uy
}

Las arañas cambian la cutícula durante los procesos de muda a lo largo de su desarrollo, pero sólo las hembras del grupo de arañas migalomorfas continúan mudando después de la muda de maduración. El tamaño corporal alcanzado durante la adultez es un atributo clave ya que influye directamente sobre la supervivencia, la competición, la fecundidad y otros componentes del fitness. El tamaño tiene consecuencias sobre el dimorfismo sexual de la especie, que comprende las diferencias morfológicas, fisiológicas o comportamentales entre machos y hembras. Grammostola vachoni es una tarántula endémica de Argentina que habita exclusivamente en áreas montañosas de pastizal serrano. El objetivo del presente trabajo fue describir las etapas de desarrollo de G. vachoni, después de la emergencia de la ooteca, en condiciones de laboratorio. Asimismo, nos propusimos diferenciar el crecimiento entre hembras y machos inmaduros; determinar el tiempo de aparición de caracteres sexuales primarios en hembras inmaduras y analizar las posibles alometrías en el crecimiento entre los caracteres sexuales y somáticos. Se registró el desarrollo de 159 individuos que emergieron de una ooteca en laboratorio durante enero de 2013. Hasta el momento sobrevive el 58,33\%. La frecuencia de mudas por año fue de $1,69 \pm 0,26$ y $1,71 \pm 0,24$ (hembras y machos respectivamente) y el porcentaje de crecimiento corporal del $40 \%$ entre cada muda. Las espermatecas de las hembras inmaduras se observaron a partir de la séptima muda y mostraron un porcentaje de crecimiento de aproximadamente un $90 \%$ entre mudas. Se registró un crecimiento isométrico para la mayoría de los caracteres somáticos, mientras que el crecimiento de las espermatecas mostró un 
crecimiento alométrico positivo en muchas de las medidas consideradas. La información obtenida permite describir el ciclo biológico de la especie y aporta datos valiosos sobre la velocidad, el tipo de crecimiento y las posibles estrategias reproductivas durante el desarrollo.

\title{
ECOLOGíA
}

\section{Diversidad y abundancia de las "arañas cangrejos" (Thomisidae) en la franja Oriental de la Provincia del Chaco, Argentina}

\author{
Helga C. Achitte Schmutzler, Gilberto Avalos, Elena B. Oscherov
} Laboratorio de Biología de los Artrópodos, Facultad de Ciencias Exactas y Naturales y Agrimensura. Universidad Nacional del
Nordeste, Corrientes, Argentina. ceciliaachitte@hotmail.com; etin 99@yahoo.com; eboscherov@yahoo.com.ar

La franja Oriental de la Provincia del Chaco integra la lista de Sitio RAMSAR con el nombre Humedales Chaco. Esta zona destinada a la conservación presenta una gran varie dad de unidades ambientales y se estima que alberga distintas composiciones de la araneofauna que hasta el momento ha sido poco estudiada, particularmente no se registran investigaciones acerca de las "arañas cangrejos". La familia Thomisidae, de distribución mundial, está representada en Argentina por 36 especies distribuida en 17 géneros. El presente trabajo tiene como objetivo contribuir al conocimiento acerca de la riqueza y abundancia de esta familia en el Sitio RAMSAR; para ello se realizaron capturas de arañas mediante golpeteo de follaje, captura manual y aspirado; en bosques y pastizales de siete localidades del Sitio. Los muestreos se realizaron durante los meses estivales, durante los años 2013-2016. Para caracterizar la diversidad de especies de Thomisidae se utilizaron curvas de interpolación/extrapolación basadas en los números de Hill: ${ }^{0} \mathrm{D}(\mathrm{q}=0,1,2)$. Para comparar los patrones de abundancia se elaboraron curvas de Whittaker. Los bosques presentaron la mayor abundancia y riqueza $(\mathrm{N}=229, \mathrm{~S}=31)$ respecto a los pastizales $(\mathrm{N}=57, \mathrm{~S}=8)$. El bosque es significativamente más diverso que el pastizal para $\mathrm{q}=0$ y q=1, en ambos casos la extrapolación sugiere que no podrán igualarse al aumentar el esfuerzo de muestreo. No obstante, para la diversidad de especies dominantes $(\mathrm{q}=2)$ no hubo diferencias significativas. Los patrones de abundancia mostraron en el bosque una dominancia bien marcada por unas pocas especies, $\mathrm{y}$ en el pastizal un ensamble más equitativo. Muchos de los Thomisidos hallados no han podido ser identificados a nivel de especie, como las del género Tmarus, es probable que sean nuevas especies o citas para Argentina. Este trabajo representa un aporte al conocimiento de la ecología de Thomisidae en nuestra Región. 


\title{
Diversidad taxonómica de los ensambles de arañas (Araneae) en sectores con distinto manejo forestal del bosque pedemontano del noroeste argentino
}

\author{
Ana S. Alcalde ${ }^{1}$, Natalia Politi ${ }^{1}$, Sandra M. Rodríguez Artigas ${ }^{2}$, José A. Corronca ${ }^{2}$, Luis O. Rivera ${ }^{1}$ \\ ${ }^{1}$ Universidad Nacional de Jujuy. Instituto de Ecorregiones Andinas. Consejo Nacional de Investigaciones Científicas y Técnicas. \\ Alberdi 47. San Salvador de Jujuy (4600), Jujuy, Argentina. \\ ${ }^{2}$ Universidad Nacional de Salta. Consejo Nacional de Investigaciones Científicas y Técnicas. Av. Bolivia 5150 (4400), Salta \\ Argentina. as.alcalde@conicet.gov.ar
}

Las arañas constituyen uno de los grupos de artrópodos depredadores más diversos en los ecosistemas terrestres, especialmente en bosques tropicales. El bosque pedemontano (BP) se caracteriza por una exuberante biodiversidad y por ser uno de los ecosistemas más amenazados de la región andina debido a actividades productivas sin planificación. Es por ello que investigaciones enfocadas en el estudio de la diversidad de arañas son particularmente importantes como aporte para su conservación. El objetivo de éste trabajo fue determinar la composición y abundancia de los ensambles de arañas presentes en sectores del BP con diferente manejo forestal, y asociarlas con la estructura del hábitat en cada sitio. Se muestrearon tres sitios sin aprovechamiento forestal (R) y tres sitios con aprovechamiento forestal (A) en el BP de las provincias de Salta y Jujuy. Se colocaron 50 trampas de caída y se midieron variables ambientales por sitio durante los meses de mayo y noviembre de 2015, 2016 y 2017. Se recolectaron 2425 arañas, pertenecientes a 141 morfoespecies y 37 familias. Los escalamientos multidimensionales no métricos mostraron que tanto morfoespecies como familias se ordenaron según el tipo de manejo que se hace del bosque. Los análisis canónicos de correspondencia mostraron que los ensambles de arañas en $\mathrm{R}$ se asocian a un mayor porcentaje de cobertura vegetal de más de 10 metros de altura, mientras que en A se asocian a un mayor porcentaje de cobertura vegetal de no más de 3 metros de altura. El tipo de manejo que se realiza sobre el bosque modifica la estructura vegetal del mismo, modelando los ensambles de arañas asociados a ellos. Entender cómo se estructuran éstas comunidades en sitios con buen estado de conservación es importante para delinear pautas de aprovechamiento sustentable.

\section{Patrones de distribución de los arácnidos en la provincia biogeográfica Subantártica: un enfoque numérico}

\author{
María J. Apodaca, Elián L. Guerrero
}

División Plantas Vasculares. Museo de La Plata. Facultad de Ciencias Naturales y Museo, Universidad Nacional de La Plata. Paseo del Bosque s/n. 1900, La Plata, Argentina. CONICET. eguerrero@fcnym.unlp.edu.ar; apodaca@fcnym.unlp.edu.ar 
Los bosques de Nothofagus que caracterizan a la región andina de la Patagonia Argentina (provincia biogeográfica Subantártica) han recibido la atención de diversos autores por su biota endémica y sus conexiones biogeográficas con áreas lejanas del hemisferio sur. En este trabajo se propone evaluar mediante técnicas cuantitativas si esta área es homogénea o puede ser subdividida. Para ello se recolectó información de distribución geográfica de especies Argentinas de arácnidos, se cuadriculó el área de estudio y se realizó un análisis de agrupamientos a partir de matrices de similitud en las que se varía el tamaño de las cuadrículas $(25 \times 25$ y $50 \times 50 \mathrm{~km})$ y el coeficiente de similitud utilizado (Jaccard, Simpson y Dice). Se seleccionaron los órdenes Opiliones (4 familias; 15 especies), Araneae ( 2 familias; 8 especies) y Pseudoscorpiones (9 familias; 20 especies). Como resultado se pudo observar que las distribuciones de los taxones estudiados no son homogéneas, por lo que se pudieron encontrar distintos tipos de asociaciones entre cuadrículas, con leves variaciones de acuerdo a los coeficientes y al tamaño de las mismas. Por otro lado, se observó que muchas especies son endémicas de tan solo una cuadricula, por lo que no contribuyen a agruparlas por su similitud. Sin embargo la alta proporción de endemismos restringidos también puede ser entendida como antagónica con la visión de la provincia Subantártica como una gran unidad indivisible. Se advierte sin embargo que los resultados pueden contener cierto sesgo por escasez de registros y por no haber incluido el sector de bosques subantárticos de Chile en el análisis, por lo que a futuro se prevé incrementar la cantidad de registros incluyendo al país limítrofe para lograr una regionalización comprehensiva.

\title{
IMPORTANCIA SANITARIA
}

\section{Primera alarma detectora de escorpiones}

\author{
Francisco L. Giambelluca ${ }^{1,2}$, Jorge Osio ${ }^{1}$, José A. Rapallini ${ }^{1}$, Luis A. Giambelluca ${ }^{2}$ \\ ${ }^{1}$ Centro de Técnicas Analógico-Digitales (CeTAD, Facultad de Ingeniería, UNLP). Calle 116 y 48, $2^{\circ}$ piso, La Plata. \\ frangiambe@gmail.com ; jorgeosio@gmail.com; josrap@gmail.com \\ ${ }^{2}$ CEPAVE, (CONICET-UNLP-CCT La Plata). Facultad de Ciencias Naturales y Museo, Universidad nacional de La Plata. \\ giambelluca@cepave.edu.ar
}

Los escorpiones se caracterizan por su fluorescencia ante el estímulo de una luz UV. Bajo este principio se patentó un dispositivo el cual aprovecha esta cualidad para identificarlos y hacer una alarma detectora de los mismos. Para la realización de esta alarma se utilizó el procesamiento digital de imágenes, analizando pixel a pixel la imagen capturada desde una webcam en busca del color característico de la fluorescencia. Para realizar el procesamiento de imágenes se utilizaron las librerías de código abierto OpenCV en lenguaje de programación $\mathrm{C}$, mediante el entorno de desarrollo Code::Blocks también de código abierto, una webcam, una notebook y una fuente de luz UV. La detección del color se realizó mediante la utilización del formato de imagen HSV (Hue, Saturation, Value), observando sólo el valor Hue que es el de nuestro interés para conocer el color del pixel. Con el fin de optimizar el funcionamiento del 
programa, requerido para dicho procesamiento, se implementó un algoritmo de detección de movimiento mediante procesamiento de imagen con el fin de solo procesar las secciones de la captura (imagen de un cuadro capturado por la webcam) en las cuales haya habido movimiento. La detección de movimiento se realizó haciendo la diferencia entre dos imágenes en blanco y negro (para facilitar el procesamiento) tomadas en diferente tiempo, esta se hizo pixel a pixel entre las dos matrices (una de cada imagen). Si dicha diferencia superaba un umbral mínimo entonces habría movimiento y el programa evalúa la presencia del color en dichos pixeles, alertando la presencia del escorpión en caso de encontrarlo. En este trabajo se realizaron pruebas con ejemplares de Tityus trivittatus y con individuos de los órdenes Isopoda, Coleoptera y Blattodea como controles.

\title{
Primeros registros de garrapatas (Acari: Ixodidae) para el Departamento Canindeyú, Paraguay
}

\author{
David J. Guerrero ${ }^{1}$, Valeria N. Debárbora ${ }^{2}$, Bolivar Garcete-Barrett ${ }^{1}$, John A. Kochalka ${ }^{1}$, Myriam \\ C. Velázquez ${ }^{3}$, Fredy Ramírez-Pinto ${ }^{3}$, Federico Pontón ${ }^{4}$, Belén Natalini ${ }^{4}$, Martín Kowalewski ${ }^{4}$ \\ ${ }^{1}$ Museo Nacional de Historia Natural del Paraguay. San Lorenzo, Departamento Central, Paraguay. megadavidjgo@hotmail.com, \\ bolosphex@gmail.com, johnkochalka@gmail.com \\ ${ }^{2}$ Laboratorio de Biología de los Parásitos. Facultad de ciencias exactas y Naturales y Agrimensura, \\ Universidad Nacional del Nordeste (UNNE-CONICET), Argentina. deborva@hotmail.com \\ ${ }^{3}$ Fundación Moisés Bertoni, Asunción, paraguay.mvelazquez@mbertoni.org.py, framirez@mbertoni.org.py \\ ${ }^{4}$ Estación Biológica de Usos Múltiples de Corrientes (EBCo), Museo Argentino de Ciencias Naturales- CONICET, Argentina. \\ federicoponton@gmail.com, belennatalini@gmail.com,martinkow@gmail.com
}

En Paraguay, en el Departamento Canindeyú, se encuentra la Reserva Natural del Bosque Mbaracayú, que protege uno de los últimos remanentes de Bosque Atlántico en Paraguay. La reserva enfrenta varias amenazas y conflictos, entre los que se puede citar el aumento del efecto isla, el crecimiento poblacional explosivo de la zona y la persistencia y aumento de las actividades furtivas. Las alteraciones de los ecosistemas pueden facilitar la aparición o dispersión de enfermedades y uno de los factores de expansión son los vectores como las garrapatas. Hasta la fecha en Paraguay se han registrado 35 especies de garrapatas pertenecientes a la Familia Argasidae Koch, 1844 e Ixodidae Koch, 1844. Este trabajo presenta las primeras citas de garrapatas de la Familia Ixodidae para el Departamento Canindeyú y contribuye al conocimiento de la fauna de garrapatas asociadas a mamíferos silvestres en la Reserva Natural del Bosque Mbaracayú. Se reporta por primera vez a las especies Amblyomma brasiliense Aragão 1908, Amblyomma parvum Aragão 1908 y Amblyomma pacae Aragão 1911 para el Departamento Canindeyú. Se presentan las primeras asociaciones de $A$. brasiliense en el Tatú hũ Dasypus novemcinctus y de A. parvum en la Akutipak Cuniculus paca. La especie $A$. parvum, registrada en este trabajo, es una garrapata que está relacionada con la trasmisión de varios patógenos de importancia en salud pública que muestra comportamiento agresivo hacia los humanos. De esta manera el presente trabajo aporta datos que podrían ayudar a futuros estudios de zoonosis transmitida por esta y otras especies en la zona, ya que los hospederos 
parasitados por las especies estudiadas en este trabajo son parte de la dieta de las comunidades indígenas que habitan al borde de la Reserva Natural del Bosque Mbaracayú.

\title{
Escorpiones en Ciudad Autónoma de Buenos Aires: un proyecto colaborativo entre la Facultad de Ciencias Exactas y Naturales (FCEN)- Universidad de Buenos Aires (UBA) y el Gobierno de la Ciudad Autónoma de Buenos Aires (GCABA)
}

\author{
Mónica S. Iglesias ${ }^{1}$, Sergio Rodríguez Gil ${ }^{2}$ \\ ${ }^{1}$ Laboratorio de Artrópodos. Departamento de Biodiversidad y Biología Experimental, Facultad de Ciencias Exactas y \\ Naturales, Universidad de Buenos Aires. Ciudad Autónoma de Buenos Aires, Argentina. ${ }^{2}$ Centro de Estudios Parasitológicos y de \\ Vectores (CEPAVE - CONICET - UNLP) iglesias@bg.fcen.uba.ar; sergiorodriguezgil@cepave.edu.ar
}

En Argentina se registran alrededor de 60 especies de escorpiones, pero sólo las del género Tityus, y en especial T. trivittatus, representan un riesgo sanitario importante. Esta especie además del poderoso veneno que posee, tiene hábitos peridomiciliarios o antrópicos lo que aumenta el riesgo para la población humana. En la Ciudad Autónoma de Buenos Aires (CABA) nunca se habían realizado trabajos de relevamiento de escorpiones de manera sistemática, en consecuencia no existía información certera acerca de su abundancia ni distribución. El aumento de los casos de escorpionismo en CABA, motivó que el gobierno firmara con la Facultad de Ciencias Exactas y Naturales de la Universidad de Buenos Aires (FCEN-UBA) un convenio con tres ejes fundamentales: 1) Búsqueda y monitoreo de escorpiones en distintas instituciones, espacios públicos y dentro de la concesión de trenes subterráneos de CABA mediante métodos de búsqueda activa y trampeo; 2) Promoción de la salud a través de divulgación de métodos de prevención y formas de proceder en caso de picaduras, orientado a la población en general y a instituciones de $\mathrm{CABA}$; 3) Investigación en distintas temáticas como ser el estudio de la reproducción, sustancias repelentes y atractantes, ciclo de vida, comportamiento y preferencia alimentaria. Estos tres ejes proporcionan la herramienta para asesorar e informar al Gobierno de CABA. El convenio contempla la posibilidad de contratar estudiantes de la carrera de Biología de la FCEN-UBA como becarios de investigación, que pueden comenzar con las primeras actividades de un biólogo. Varias de esas iniciativas se están presentando en estas Jornadas. El monitoreo sostenido en el tiempo dará un panorama completo de la situación real de la población de $T$. trivittatus en CABA, que posibilitarán realizar campañas de educación focalizadas. 


\title{
EXTENSIÓN
}

\section{Aportes del grupo de Facebook "REIVINDICANDO A LAS ARAÑAS (Vindicating SPIDERS)" a la comunidad y su función en la divulgación de la aracnología}

\author{
Luciano Peralta ${ }^{1}$, M. Florencia Ansaldi ${ }^{2}$, Mariana L. Barone ${ }^{3}$, Monserrat Manzano ${ }^{4}$, Leandro N. \\ Segovia $^{5}$, Ana Escowich ${ }^{5}$, Estrella S. Montalibet ${ }^{6}$, Sofia Alcalde ${ }^{7}$, Ana C. Denaro ${ }^{8}$ \\ ${ }^{1}$ Laboratorio de Ecología, Instituto de Investigaciones Marinas y Costeras (IIMyC; CONICET- UNMDP). Universidad Nacional de \\ Mar del Plata, Argentina. luccianoperalta@hotmail.com \\ ${ }^{2}$ Facultad de Ciencias Agrarias, Universidad Nacional de Rosario, Argentina. ansaldiflo@gmail.com \\ ${ }^{3}$ Facultad de Ciencias Exactas y Naturales, Universidad de Buenos Aires, Argentina. marianlbarone@gmail.com \\ ${ }^{4}$ Facultad de Ciencias Exactas y Naturales, Universidad Nacional de La Pampa, Argentina. monserratEmanzano@hotmail.com \\ ${ }^{5}$ Facultad de Humanidades y Ciencias, Universidad Nacional del Litoral, Argentina. lea.ns@live.com.ar; anaescowich@gmail.com \\ ${ }^{6}$ Facultad de Ciencias Naturales y Museo, Universidad Nacional de La Plata, Argentina. estrella.montalibet@gmail.com \\ ${ }^{7}$ INECOA - CONICET - Facultad de Ciencias Agrarias, Universidad Nacional de Jujuy, Argentina. biol.asalcalde@gmail.com \\ ${ }^{8}$ Facultad de Química, Bioquímica y Farmacia, Universidad Nacional de San Luis, Argentina. denaroana@gmail.com
}

El grupo de Facebook "REIVINDICANDO A LAS ARAÑAS (Vindicating SPIDERS)" https://www.facebook.com/groups/206333054031/ es administrado por aracnólogos y estudiantes avanzados de biología y carreras afines. Funciona gratuitamente desde diciembre de 2009 y cuenta con seis reglas para su correcto funcionamiento. Actualmente está conformado por más de 15.000 miembros y continúa en constante crecimiento. En el mismo se difunde información sobre arácnidos, se resuelven dudas e inquietudes, se refutan mitos y se provee de una posible determinación de los arácnidos presentes en las fotos y videos que suben los miembros. Estas identificaciones representan una aproximación sin rigor científico pero con valor didáctico. El grupo tiene como objetivos contribuir al conocimiento sobre arácnidos, atender las inquietudes de la comunidad y fomentar un cambio de actitud frente a estos animales. El propósito de este trabajo fue evaluar en qué medida los objetivos del grupo están siendo alcanzados. Para ello se realizó una encuesta Google a los miembros del grupo desde el 12-VI-2018 al 06-VII-2018, la cual fue anónima y consistió en 42 preguntas de opción múltiple agrupadas en ocho categorías. Se obtuvieron 1235 respuestas desde 20 países de América y Europa. El grupo fue calificado por sus miembros con un promedio de 9,21 sobre 10 y más del $90 \%$ consideró que su conocimiento aumentó a partir de su ingreso al mismo. Más del $30 \%$ declaró tener miedo o fobia a los arácnidos antes de conocer el grupo, sin embargo el $80 \%$ de estos manifestaron mejorías gracias al mismo. Previamente el 30,5\% mataba a los arácnidos que encontraba en sus domicilios, sin embargo sólo el $0,9 \%$ continuó esta práctica luego de participar en el grupo. Concluimos que el funcionamiento de "REIVINDICANDO A LAS ARAÑAS (Vindicating SPIDERS)" satisface en gran medida los objetivos planteados, contando con gran aceptación de sus miembros y confianza en su administración. 


\title{
App: Es araña o escorpión? Una experiencia sorprendente
}

\author{
Luis Giambelluca, Nicolás Mattone, Sergio Rodríguez Gil, Cecilia Gabellone, Sandra González, \\ Andrea Armendano, Guillermo Reboredo, Alda González \\ Centro de Estudios Parasitológicos y de Vectores (CEPAVE) (CONICET-UNLP), Facultad de Ciencia Naturales y Museo, \\ Universidad Nacional de La Plata, Argentina. giambelluca@cepave.edu.ar, mattonenicolas@gmail.com, \\ sergio.rodriguezgil@gmail.com, csgabellone@cepave.edu.ar san.gonzalez.san@gmail.com, aarmendano@hotmail.com, \\ grreboredo@yahoo.com.ar, asgonzalez@cepave.edu.ar
}

El Laboratorio de Aracnología del CEPAVE recibe durante todo el año, y especialmente en verano, consultas referidas a la aparición de arácnidos por parte de la comunidad. Esto despertó el interés de generar una herramienta que pudiera ser utilizada frente al encuentro de estos animales. La App es una aplicación digital, pública y gratuita, y está disponible para su descarga en teléfonos móviles con sistema operativo Android. El objetivo es orientar al usuario en el reconocimiento de arácnidos que encuentre, que sepa si es de interés sanitario o no, y brindarle información sobre la biología de distintas especies de Argentina. Su funcionamiento es sencillo. Frente al encuentro de un ejemplar, se le toma una foto, y se completa información sobre el lugar y el área donde se produjo el hallazgo, etc. Todo es enviado mediante la aplicación, se recibe en el laboratorio y se responde de forma inmediata. Con la información recibida se confecciona una base de datos que nos permite mapear las zonas de aparición, las conductas estacionales, los preconceptos que tienen la sociedad sobre estos arácnidos. Desde diciembre de 2017 la descarga de la App en teléfonos celulares llega a 3959 y a 1500 la cantidad de consultas efectuadas. De todas las provincias Argentinas se realizaron consultas y si bien son la mayoría, hay algunas pocas de México, Colombia, Uruguay, Honduras, Brasil y España, lo cual resulta sorprendente. Las consultas comprenden: arañas $84,35 \%$, escorpiones $11,22 \%$, insectos $2,55 \%$ y otros $1,88 \%$. Numéricamente las consultas varían estacionalmente disminuyendo en las épocas más frías. 


\title{
POSTERS
}

\section{BIOQUíMICA Y FiSIOLOGíA}

\section{Estudio del efecto de concentraciones subletales de cipermetrina sobre diferentes estados energéticos de la araña Polybetes pythagoricus}

\author{
Aldana Laino, Mónica Cunningham, Sofía Romero, Gabriel Molina, Fernando \\ García \\ Instituto de Investigaciones Bioquímicas de La Plata "Profesor Doctor Rodolfo R. Brenner" (INIBIOLP). La Plata. Argentina. \\ aldana_laino@hotmail.com; cunninghammoni@gmail.com; sofiaromero321@msn.com; g-abox@hotmail.com; \\ cfgarcia1123@yahoo.com.ar
}

El uso de pesticidas para el control de plagas impacta sobre los ecosistemas, afectando a sus organismos blanco, y a otros que directa/indirectamente están expuestos, como las arañas. $\mathrm{Su}$ respuesta frente a xenobióticos depende, entre otros factores, del estado metabólico. El presente trabajo estudia por un lado, como el insecticida cipermetrina afecta a la araña Polybetes pythagoricus en diferentes estados metabólico/energéticos (machos adultos, hembras antes y después de la vitelogénesis y juveniles), y por otro, como concentraciones subletales afectan la actividad de enzimas del sistema antioxidante (superoxido-dismutasa y catalasa) y peroxidación lipídica. Se observó que el valor de LD50 correspondiente a hembras fue 969 y 1108 ngr/gr de individuo antes y después de la vitelogénesis, 1060 ngr/gr para machos y $103 \mathrm{ngr} / \mathrm{gr}$ para juveniles. Para adultos las calorías aportadas por el glucógeno por peso de individuo fueron $3,1+/-0,17$ y $0,36+/-0,61 \mathrm{cal} / \mathrm{gr}$ para hembras antes y después de la vitelogénesis, $1,4+/-0,03$ y de $0,16+/-0,06 \mathrm{cal} / \mathrm{gr}$ para machos y juveniles respectivamente. Para los lípidos energéticos (triacilglicéridos, diacilglicéridos, ácidos grasos libres) las calorías aportadas por gramo de individuo fueron $35+/-3$ y $22+/-3$ para hembras, $32+/-2$ para machos y 56+/-6 cal/gr para juveniles. La relación triacilglicérido/ácido graso libre determinó que los juveniles poseen una mayor dinámica lipídica, (vinculada al estado metabólico diferencial). En las arañas expuestas a concentraciones subletales, se observó un incremento de 0,8 a 5,5 veces en la actividad superoxido-dismutasa en adultos en relación al control. Para catalasa no se observó incremento en machos, pero si en hembras con una media de 2 veces más. La peroxidación lipidica mostró un incremento en adultos de 0,5 veces. En juveniles no se observó incremento en la actividad superoxido-dismutasa y catalasa, pero si un gran incremento en la peroxidación lipídica (14 veces) seguramente en respuesta a la gran cantidad de especies reactivas del oxígeno producidas. 


\title{
Cambios proteicos generados durante la vitelogénesis de Polybetes pythagoricus (Araneae Sparassidae)
}

\author{
Sofia Romero, Aldana Laino, C. Fernando Garcia, Mónica Cunningham \\ Instituto de Investigaciones Bioquímicas de la Plata "Prof. Dr. Rodolfo R. Brenner" (INIBIOLP), CCT- La Plata CONICET-UNLP, \\ La Plata, Argentina. sofiaromero321@msn.com; aldana_laino@hotmail.com; cfgarcia1123@yahoo.com.ar; \\ cunninghammoni@gmail.com
}

Si bien la vitelogénesis es uno de los procesos más importantes que ocurren en las especies ovíparas debido a que puede determinar la supervivencia de los embriones, la bioquímica de este proceso en arañas aún no ha sido esclarecida. Durante la vitelogénesis, se sintetizan proteínas, carbohidratos y lípidos que serán almacenados dentro de los oocitos en crecimiento, los cuales tendrán como destino final el huevo. En el presente trabajo, considerando que todos los procesos biológicos dependen de la presencia y actividad de las proteínas, se analizaron los cambios proteicos en los divertículos intestinales, hemolinfa y ovarios de hembras en diferentes estadios vitelogénicos de Polybetes pythagoricus (pre-vitelogénico, vitelogénico temprano, vitelogénico y post-vitelogénico) y su relación con la composición proteica del huevo. A lo largo de la vitelogénesis se pudo observar un aumento en la cantidad de proteínas totales en los divertículos intestinales, hemolinfa y ovarios de las hembras (estadios pre-vitelogénico, vitelogénico temprano y vitelogénico), observándose una disminución de estos niveles luego de la puesta (post-vitelogénica). Por otra parte, aplicando métodos inmunológicos y determinando la secuencia N-terminal, se pudo demostrar la presencia de hemocianina en huevos y en la lipovitelina 2, como también su acumulación en el ovario a lo largo del proceso de vitelogénesis. Este estudio es el primero en proporcionar las bases de la dinámica proteica durante la vitelogenesis para el Orden Araneae, estableciendo la coexistencia de tres orígenes diferentes de las proteínas: un origen predominantemente ovárico que involucra las subunidades de 120, 75, 46 y $30 \mathrm{kDa}$; otro extraovárico a partir de los divertículos intestinales, representado por un péptido de $170 \mathrm{kDa}$, y finalmente un origen hemolinfático, representado por el monómero de hemocianina. 


\title{
ECOTOXICOLOGíA
}

\section{Estudio preliminar de la araneofauna en cultivos de morrón (Capsicum annuum $L$.) en invernáculos con sistema agrícola convencional y en transición agroecológica}

\author{
Maria José Deza ${ }^{1}$, Ruben Cruz $^{1}$, Carmen Viera ${ }^{2}$, Marco A. Benamú ${ }^{1}$ \\ ${ }^{1}$ Laboratorio de Ecotoxicología de Artrópodos Terrestres, Centro Universitario de Rivera, Universidad de la República, Uruguay. \\ ${ }^{2}$ Entomología, Facultad de Ciencias, Universidad de La Republica, Uruguay \\ mdeza@fcien.edu.uy, mbenamu@cur.edu.uy, rucruzagrifam@hotmail.com,cviera@fcien.edu.uy
}

La producción de morrón (Capsicum annuum) es importante en Uruguay. En 2015 fue el 3,8\% del ingreso total del Mercado Modelo de Montevideo. Una característica diferencial, es que en su mayoría se desarrolla en invernáculos, sobre todo en el litoral Norte, cuya producción representa un $81 \%$ del total a nivel nacional. Este estudio busca comparar la variación en la composición, abundancia e importancia de la araneofauna en cultivos de morrón bajo cubierta, con manejo de un sistema agrícola convencional (SAC) y otro en transición agroecológica (SATA). El presente trabajo se realiza en la localidad de Bella Unión, Departamento de Artigas (Uruguay). Se muestrean ambos sistemas agrícolas utilizando trampas Pitfall dentro de los invernáculos. El análisis preliminar de la araneofauna dio como resultado 94 especies (65 para SATA y 38 para SAC), compartiendo 23 especies en común, las más frecuentes pertenecieron a las familias Linyphiidae y Lycosidae. El mayor número de singletons (SATA:25, SAC:23) que doubletons (SATA:13, SAC:7), indicaría que hay un número alto de especies raras en donde la curva no presenta una tendencia de estabilidad y requeriría de un mayor esfuerzo de muestreo. La mayor diversidad según Margalef fue en SATA (10.64) en comparación con SAC (8.54), mientras que con Shannon fue de 3.113 para SATA y 3.363 para SAC, presentando diferencias estadísticas signicativas $(\mathrm{t}=-1.938, \mathrm{P}>0.05)$. La dominancia (Simpson) se vio reflejada en SAC (0.95) con respecto a SATA (0.89). La similaridad entre ambos sistemas agrícolas según Jaccard, fue $28.7 \%$. Con estos resultados preliminares, se podría comprobar como la variación en la composición, abundancia y diversidad de la araneofauna podría verse afectada, según el sistema agrícola analizado, siendo el SAC el que presenta un desequilibrio a nivel trófico, teniendo en cuenta que el uso de plaguicidas estaría afectando a las arañas como enemigos naturales. 


\title{
ETOLOGÍA
}

\section{Comportamiento depredador en Tityus fuhrmanni: uso del aguijón frente a tres tipos de presa con morfotipos contrastantes}

\author{
Alejandra Arroyave Muñoz ${ }^{1,2}$, Luis F. García ${ }^{3}$ \\ ${ }^{1}$ Programa de Ofidismo y Escorpionismo, Universidad de Antioquia, Medellín, Colombia. \\ ${ }^{2}$ Programa para El Desarollo de las Ciencias Básicas, Universidad de la República, Montevideo, Uruguay. \\ ${ }^{3}$ Centro Universitario Regional del Este, Treinta y Tres, Uruguay. lejasama@gmail.com; luysgarcia@gmail.com
}

La captura condicional es un factor determinante para los depredadores generalistas, teniendo en cuenta que les permite acceder a distintos tipos de presa. A pesar de lo anterior son pocos los estudios que han evaluado el efecto del tamaño y tipo de presa en escorpiones. En el presente estudio se analizó el comportamiento depredador del escorpión Tityus fuhrmanni frente a presas con distintos tamaños y morfologías. Para lo anterior se utilizaron 20 hembras y 20 machos adultos de T. fuhrmanni a los cuales se les ofreció presas con morfologías contrastantes, siendo estas: arañas (Ctenus sp.) consideradas como presas peligrosas debido a la presencia de colmillos venenosos, grillos (Acheta domestica) considerados como presas medianamente peligrosas debido a su capacidad de patear y morder y cucarachas (Periplaneta americana) consideradas como presas no peligrosas. Por cada experimento se registró el uso del aguijón, número de picaduras y tiempo de la picadura. Con el fin de evaluar el efecto del tamaño, éste se incluyó como covariable en los análisis realizados. Se encontró que el uso del aguijón y número de picaduras fue similar a nivel de todas las presas evaluadas. Sin embargo, se encontraron diferencias significativas entre el tiempo de picadura que fue casi cinco veces mayor en el caso de las arañas en relación con grillos y cucarachas. No se encontró un efecto significativo del tamaño en ninguno de los parámetros evaluados. Estos resultados sugieren que si bien T. fuhrmanni usa una estrategia de captura basada en el uso del aguijón para la captura de presas, la principal diferencia se encuentra en el tiempo de las picaduras, el cual es mayor en las presas más peligrosas y podría relacionarse con la inyección de una mayor cantidad de veneno. Futuros estudios evaluarán si la cantidad de veneno empleada varía también según la presa. 


\title{
Consistencia del comportamiento en interacciones inter-sexuales: una especie de araña como modelo
}

\author{
Lucia Calbacho-Rosa ${ }^{1,2}$, Franco Cargnelutti ${ }^{1,2}$, Alex Córdoba-Aguilar ${ }^{3}$, Alfredo V. Peretti ${ }^{1,2}$ \\ ${ }^{1}$ Laboratorio de Biología Reproductiva y Evolución, Facultad de Ciencias Exactas, Físicas y Naturales, Universidad Nacional de \\ Córdoba, Argentina. \\ ${ }^{2}$ Instituto de Diversidad y Ecología Animal (IDEA), Consejo Nacional de Investigaciones Científicas y Técnicas (CONICET). \\ ${ }^{3}$ Departamento de Ecología Evolutiva, Instituto de Ecología, Universidad Nacional Autónoma de México, México. \\ luciacalbacho@gmail.com, francocarg@gmail.com, acordoba@iecologia.unam.mx, aperettibec@gmail.com
}

En un contexto sexual, se espera que las hembras basen su elección de pareja en los comportamientos que los machos realizan durante el cortejo, ya que tales comportamientos se asocian con la calidad de este. La estridulación es una forma de comunicación femenina en los artrópodos, por ejemplo, las arañas. Este es un rasgo interesante del cortejo de algunas arañas Pholcidae para ser estudiado desde la perspectiva de comunicación inter-sexual. Nuestros objetivos son: 1) determinar posibles diferencias en la frecuencia de ocurrencia del comportamiento de estridulación entre hembras en interacciones inter-sexuales, 2) establecer la consistencia femenina en la estridulación a lo largo de interacciones sucesivas, y en diferentes escenarios de comunicación inter-sexual dentro del contexto sexual: simétricos (es decir, machos cortejan y hembras estridulan) vs. asimétricos (es decir, machos cortejan y hembras no estridulan y viceversa). Para nuestro estudio utilizamos 24 hembras de la especie Holocnemus pluchei (Pholcidae) y comparamos la frecuencia de estridulación entre ellas, en cada una a lo largo 10 interacciones sucesivas, así como en diferentes escenarios de comunicación (comunicación simétrica vs. comunicación asimétrica). Nuestros resultados mostraron diferencias en la frecuencia de estridulación entre las diferentes hembras, pero no en sus respectivas interacciones sucesivas. Sin embargo, mostraron diferencias en la frecuencia de estridulación en diferentes escenarios (mayor frecuencia durante las interacciones sexuales con comunicación simétrica). Las diferencias entre las hembras se pueden explicar debido a su decisión de aparearse o no (tal vez las hembras que estridulen con mayor frecuencia son las más exigentes). Las hembras fueron consistentes en el tiempo, lo que implica que cada interacción no afectó su comportamiento posterior. Por el contrario, las hembras no fueron consistentes en los diferentes escenarios de comunicación, por lo que la estridulación parece estar influenciada principalmente por el comportamiento de los machos. 


\title{
“Con maña, caza a la mosca la araña": ecología y comportamiento de dos especies de Thomisidae en espacios urbanos
}

\author{
Mariana Ferreyra ${ }^{1}$, Raquel M. Gleiser ${ }^{1,2}$ \\ ${ }^{1}$ Centro de Relevamiento y Evaluación de Recursos Agrícolas y Naturales. Instituto Multidisciplinario de Biología Vegetal \\ CONICET - Universidad Nacional de Córdoba, Argentina. \\ ${ }^{2}$ Cátedra de Ecología, Facultad de Ciencias Exactas, Físicas y Naturales, Universidad Nacional de Córdoba , Argentina. \\ ferreyramar4@gmail.com; raquel.gleiser@unc.edu.ar
}

Las áreas urbanas han experimentado un crecimiento asombroso en el último siglo. Con frecuencia, los efectos negativos de la urbanización sobre los organismos pueden ser observados a simple vista, pero algunas especies son favorecidas por los recursos y las nuevas condiciones ofrecidas en estos ambientes o son resilientes a los cambios. Para comunidades de arañas se han reportado resultados variados y contrastantes. La familia Thomisidae es un modelo interesante de estudio porque es fácil de detectar a simple vista y observar sin causar cambios notables en su comportamiento. En la ciudad de Córdoba, observamos una gran variabilidad en riqueza y abundancia entre espacios verdes que sugiere que los factores locales serían más relevantes que factores a nivel de paisaje para explicar los patrones comunitarios de esta familia. Los criterios o las estrategias para seleccionar sitios de caza por parte de Misumenops pallidus y en especial por Misumenops maculissparsus han sido poco estudiados. Al igual que en la mayoría de los estudios de este grupo, no se comprende claramente los efectos de señales provistas por la calidad de la flor o por la abundancia de presas, variables difíciles de diferenciar en estudios de campo. Los objetivos específicos de la propuesta son: (i) Evaluar el uso por las arañas cangrejo de flores o inflorescencias frecuentes en espacios verdes urbanos, como sitios de captura de presas; (ii) Determinar los principales tipos de presas consumidas; (iii) Evaluar la amplitud y superposición de nichos tróficos y de parche (flor) de las especies de araña cangrejo, y si estos factores interactúan. Como estrategia de estudio se proponen una combinación de observaciones de campo con experimentos en laboratorio. Con este proyecto esperamos contribuir a la compresión de los mecanismos y procesos ecológicos que determinan los patrones de riqueza y abundancia de especies en espacios verdes urbanos.

\section{Comportamiento de alimentación y captura de Tityus trivittatus, una especie de interés sanitario}

\author{
Juan Kopp, Iván A. López, Mónica S. Iglesias
}


Tityus trivittatus (Buthidae), presente en la Ciudad Autónoma de Buenos Aires, es un escorpión que ha tomado mayor relevancia sanitaria, debido al incremento en el número de casos de accidentes por picaduras en áreas urbanas. El objetivo de este trabajo fue $\mathrm{c}$ aracterizar el comportamiento de captura y alimentación de esta especie utilizando como presa Gryllus assimilis. Los escorpiones $(\mathrm{N}=28)$ se introdujeron en sendos recipientes plásticos circulares de $13 \mathrm{~cm}$ de diámetro por $6 \mathrm{~cm}$ de alto, con sustrato de arena. Luego en cada habitáculo se colocó un grillo en el polo opuesto al predador. Se filmó durante 10 minutos la interacción predador - presa, contabilizando a partir del primer contacto. Se analizó cada video resultante y se identificaron los comportamientos que finalizaron con la captura y alimentación. Se observó la siguiente cronología con mayor frecuencia: 1-posición de alerta (apenas es introducida la presa) donde el escorpión extiende sus palpos hacia adelante y posiciona la cola verticalmente en el plano sagital; 2- la orientación hacia la presa; 3- el agarre; 4- el picado; 5la oscilación lateral de la cola; 6- comido parcial de presa; 7-arrastre de presa con palpos. En los casos donde el escorpión no comió o capturó a la presa, también se observaron los comportamientos de: alerta, orientación hacia la presa, tanteo de la presa con pedipalpos y el intento de agarre. Con estos resultados se confeccionó un etograma. Cabe destacar que no se observaron algunos comportamientos presentes en Tityus uruguayensis, como el arrastre de la presa con quelíceros, el pseudopicado, la oscilación sagital del telson y la búsqueda de la presa picada.

\title{
Medición de la fuerza adherencia por microscopía de fuerza atómica en las patas de la tarántula Eupalaestrus weijenberghi (Araneae, Theraphosidae)
}

\author{
Fernando Pérez-Miles ${ }^{1}$, Gonzalo Rosso ${ }^{2}$ \\ 'Sección Entomología, Facultad de Ciencias, Universidad de la República, Uruguay, myga@fcien.edu.uy. \\ ${ }^{2}$ Biotechnology Center of the TU Dresden, Dresden, Germany
}

Las patas de las tarántulas se caracterizan por presentar setas adhesivas en la superficie ventral de sus tarsos y parte de sus metatarsos. Estas setas organizadas en escópulas ventrales y fascículos subungueales apicales les permiten trepar superficies lisas verticales, incluso mantenerse adheridas de forma invertida en superficies horizontales. Cada seta adhesiva está cubierta de numerosas sétulas espatuladas. Considerando la densidad de las sétulas $(3.05 \pm$ .55) y el área media de la escópula más el fascículo ungueal $\left(23 \mathrm{~mm}^{2}\right)$ se estiman en 69 millones de sétulas por pata, totalizando 552 millones de sétulas en las 8 patas. Utilizando un microscopio de fuerza atómica para medir la adherencia de cáda sétula, se obtuvieron valores que rondan los $40 \mathrm{nN}$, con lo cual se estima una fuerza de adherencia máxima de $22 \mathrm{~N}$ en contacto total de las ocho patas. Considerando el peso medio de los machos de esta especie ( $5 \mathrm{~g})$, estos contarían con un factor de seguridad de 433, lo que indica que la adherencia soportaría 433 veces el peso de la araña. Sorprendentemente, la fuerza de adherencia resultó casi 1000 
veces mayor que la calculada para saltícidos con un peso 340 veces menor. El factor de seguridad resultó 2.5 veces mayor en E. weijenberghi que en el saltícido Evarcha arcuata. Los cálculos en ambas especies fueron estimados en condiciones teóricas de adherencia máxima que raramente se darían en la naturaleza. Observaciones realizadas sobre vidrio indican que en E. weijenberghi utiliza solamente un área de apoyo de aproximadamente el $15 \%$ de sus órganos adhesivos cuando trepa. Esto disminuye la adherencia de los cálculos teóricos iniciales a una fuerza de $3.31 \mathrm{~N}$ y un factor de seguridad de 64. La alta adherencia encontrada puede explicarse por requerimientos extremos de la locomoción, especialmente en terafósidas arborícolas, pero también con la captura de presas.

\title{
Descripción del cortejo multimodal en la araña donadora de regalos nupciales Trechaleoides keyserlingi (Trechaleidae)
}

\author{
Karen Rinaudo ${ }^{1}$, Manuel Zeballos ${ }^{1}$, María J. Albo ${ }^{2}$, Alfredo. V. Peretti ${ }^{1}$ \\ ${ }^{1}$ Laboratorio de Biología Reproductiva y Evolución, Facultad de Ciencias Exactas, Físicas y Naturales, Universidad Nacional de \\ Córdoba, Argentina- Instituto de Diversidad y Ecología Animal, CONICET-UNC. \\ ${ }^{2}$ Departamento de Ecología y Biología Evolutiva, Instituto de Investigaciones Biológicas Clemente Estable, Montevideo, Uruguay \\ karendelpilarrinaudo@gmail.com; manuzeballos.c@gmail.com; mjalbograna@gmail.com; \\ aperetti@unc.edu.ar
}

El comportamiento reproductivo en arañas está determinado por un feedback de información entre ambos sexos que involucra múltiples sistemas sensoriales en diferentes etapas del cortejo. Un caso particular es el de los machos de la araña Trechaeloides keyserlingi, que, dentro de su comportamiento de apareamiento, realizan regalos nupciales como una estrategia de cortejo, el cual consiste usualmente en una presa envuelta en seda. Esta especie es un buen modelo para estudiar el cortejo en arañas donadoras de regalos nupciales ya que existe escasa información sobre su comportamiento sexual. El objetivo de este trabajo es describir el cortejo de la araña $T$. keyserlingi, identificando las unidades de comportamiento y su asociación temporal con la construcción del regalo. Se expusieron machos a hembras, ambos adultos, en terrarios acondicionados con substrato del lugar de colecta. Se filmó su comportamiento durante 1,5 hs promedio finalizando al ocurrir cópula o al existir intento de canibalismo. Mediante el uso del programa JWatcher se calcularon las frecuencias de aparición y duraciones de las unidades de comportamiento. A la fecha se han identificado las siguientes unidades de los machos: vibraciones de patas delanteras, movimientos pedipalpares secuenciales y preparación del regalo nupcial. Mientras que las unidades comportamentales identificadas en las hembras fueron: hiperflexión, aceptación del regalo, rechazo (huída), toque con primer par de patas (ambigüedad). Se confeccionó un diagrama de flujo que refleja las transiciones entre las unidades del macho, a la vez de la asociación con las unidades exhibidas por la hembra. Encontramos que el cortejo de T. keyserlingi se caracteriza por distintos canales de comunicación, tales como: mecánica (vía vibraciones de patas delanteras), dual mecánica-visual (vía movimientos pedipalpares secuenciales), y mixta mecano-visual-gustatorial (vía regalo 
nupcial). Se discuten los datos obtenidos desde perspectivas de selección sexual y comunicación multimodal.

\title{
SISTEMÁTICA
}

\section{Estudio sistemático de los Opiliones (Arthropoda: Arachnida) depositados en una colección de ámbar báltico}

\author{
Dayán G. Giraldo, Abel Pérez González \\ Museo Argentino de Ciencias Naturales (MACN); Buenos Aires, Argentina. dayan-guillen@hotmail.com; abelaracno@gmail.com
}

Se ofrecen los resultados preliminares del estudio de una serie de ejemplares fósiles pertenecientes a la colección de ámbar Báltico del Dr. George Poinar (Universidad Estatal de Oregón, EE.UU.), los cuales fueron enviados para su estudio a la División de Aracnología del MACN. Las muestras consisten en 7 piezas de ámbar del Eoceno (ca. 30 MDA) procedentes de Escocia. Los ejemplares fueron analizados y fotografiados con auxilio de un microscopio estereoscópico con cámara digital acoplada y también fueron escaneados en el microtomógrafo (MicroCT Bruker SkyScan 1173) de la empresa YPF Tecnología (Y-TEC), en la ciudad de La Plata. Las imágenes del tomógrafo se procesaron en el software Amira. De las siete muestras analizadas 5 pertenecían a especies previamente descritas para ámbar báltico: Proholoscotolemon nemastomoides (Koch \& Berendt, 1854) n. comb. (muestra_1); Dicranopalpus cf. Ramiger (Koch \& Berendt, 1854) (muestra_2 un ejemplar adulto y muestra_3 un posible juvenil); Histricostoma tuberculatum (Koch \& Berendt, 1854) (muestra_4); Amilenus deltshevi (Dunlop \& Mitov, 2009) (muestra_5) y Leiobunum longipes (Menge, 1854) (muestra_6). La muestra 7 pertenece a una nueva especie de Phalangiidae (Eupnoi) cuya ubicación genérica todavía se encuentra en estudio. La especie se diferencia de otros Phalangiidae por la morfología de los pedipalpos y por la armadura y grosor de los fémures de las patas locomotoras. El ejemplar de Amilenus deltshevi también resulta particularmente interesante, ya que nos permitirá redescribir dicha especie; sobre la base de características morfológicas de ejemplares adultos, los cuales eran desconocidos hasta el presente. 


\title{
Nuevos aportes a la taxonomía y distribución de las especies de Actinopus (Mygalomorphae, Actinopodidae) en el sur de la provincia de Buenos Aires
}

\author{
Micaela Nicoletta ${ }^{1}$, Duniesky Ríos-Tamayo ${ }^{2}$, Nelson Ferretti $^{3}$ \\ ${ }^{1}$ Departamento de Biología, Bioquímica y Farmacia, Universidad Nacional Del Sur, Bahía Blanca, Argentina. \\ mmnicolettal@gmail.com \\ ${ }^{2}$ Unidad Ejecutora Lillo (CONICET-Fundación Miguel Lillo), San Miguel de Tucumán, Argentina. duniesky1979@gmail.com \\ ${ }^{3}$ Instituto de Ciencias Biológicas y Biomédicas del Sur (INBIOSUR-CONICET-UNS), Bahía Blanca, Argentina. \\ nferretti@conicet.gov.ar
}

El género Actinopus Perty, 1833 es el más diverso de la familia Actinopodidae con 49 especies de arañas albañiles presentes sólo en América, de las cuales 23 han sido citadas para Argentina. Son arañas de tamaño mediano caracterizadas por un tegumento glabro, fuertes espinas en las patas, rastrillo en los quelíceros, ocho ojos en dos filas y fóvea procurva. El objetivo del presente trabajo es describir la hembra de A. puelche Ríos-Tamayo \& Goloboff, 2018, desconocida hasta el momento, y presentar nuevas citas que amplían la distribución geográfica de $A$. puelche y de A. patagonia Ríos-Tamayo \& Goloboff, 2018. Para esto, se examinaron 24 ejemplares de la colección de Zoología de Invertebrados II, Universidad Nacional del Sur. Los especímenes se observaron y fotografiaron usando una lupa estereoscópica Leica S8APO. Se analizaron 4 hembras capturadas en Funke, Sierra de la Ventana, localidad tipo de A. puelche. La especie A. casuhati Ríos-Tamayo \& Goloboff, 2018 se encuentra en simpatría con A. puelche. Sin embargo, la hembra descripta difiere principalmente de $A$. casuhati por la forma de su espermateca, de sección cuadrangular y lóbulos poco desarrollados, y por poseer unas 45 espinas retrolaterales en la tibia II, mientras que $A$. casuhati posee unas 90 espinas. La hembra descripta se halló en una cueva de $13,12 \mathrm{~mm}$ de diámetro de entrada con una tapa de $16,49 \mathrm{~mm}$ de diámetro. Finalmente, se presentan nuevas citas de $A$. puelche y A. patagonia para la localidad de Bahía Blanca (Cueva de los leones). En conclusión, se aportan nuevos datos al conocimiento de la taxonomía y distribución del género Actinopus en Argentina, particularmente en el sur de la provincia de Buenos Aires. 


\title{
Primeros registros de Scytodes univittata Simon, 1882 (Araneae: Scytodidae) en Argentina
}

\author{
Luciano Peralta $^{1}$, Leandro N. Segovia ${ }^{2}$, M. Florencia Ansaldi ${ }^{3}$, Ana Escowich ${ }^{2}$, Mariana Griotti $^{4}$ \\ ${ }^{1}$ Laboratorio de Ecología, Instituto de Investigaciones Marinas y Costeras (IIMyC; CONICET-UNMDP). Universidad Nacional de \\ Mar del Plata, Argentina. luccianoperalta@hotmail.com \\ ${ }^{2}$ Facultad de Humanidades y Ciencias, Universidad Nacional del Litoral, Argentina. lea.ns@live.com.ar y anaescowich@gmail.com \\ ${ }^{3}$ Facultad de Ciencias Agrarias, Universidad Nacional de Rosario, Argentina. ansaldiflo@gmail.com \\ ${ }^{4}$ Instituto Argentino de Investigaciones de las Zonas Áridas (IADIZA, CCT-Mendoza), Argentina. marianitag.09@gmail.com
}

El género Scytodes Blackwall, 1864 tiene distribución mundial con 42 de sus 228 especies presentes en la región Neotropical. A las especies de este género se las denomina "arañas escupidoras" debido a que eyectan una sustancia pegajosa por sus quelíceros, con la cual inmovilizan a sus presas y se defienden de potenciales predadores. Scytodes presenta varias especies sinantrópicas que habitan tanto en el interior como el exterior de los domicilios. Scytodes univittata es una especie principalmente intradomiciliaria, originaria de Medio Oriente que ha sido introducida en España, Islas Canarias, Hawái, México, Cuba, Venezuela, Brasil, Paraguay y Chile. Hasta la fecha no ha sido registrada oficialmente para Argentina. El objetivo de este trabajo es presentar los primeros registros de $S$. univittata para Argentina y presentar resultados preliminares de su distribución en el país. Se realizaron colectas en distintas localidades de las provincias de Entre Ríos, Santa Fe, Córdoba y la Ciudad Autónoma de Buenos Aires, al mismo tiempo se revisó material de la colección Instituto Argentino de Investigaciones de Zonas Áridas (IADIZA Mendoza). Se reportan los siguientes registros de ejemplares adultos identificados como Scytodes univittata: Mendoza: Guaymallén 1 đ̊ y 1 o,

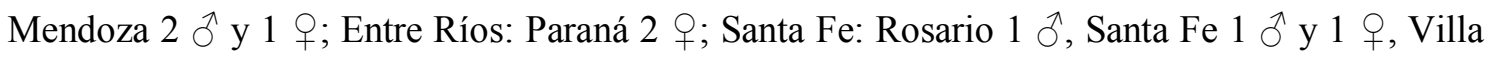
Gobernador Gálvez 1 ㅇ; Córdoba: Córdoba 2 ㅇ, Río Cuarto 1 ㅇ; Ciudad Autónoma de Buenos Aires: 1 ․ Todos los registros ocurrieron en ambientes urbanos, tres en el peridomicilio y el resto en el intradomicilio. Estos registros permiten confirmar que S. univittata se encuentra establecida en varias localidades de Argentina, aunque aún restan revisar las colecciones de algunos museos donde muy posiblemente se encuentren más ejemplares que permitan ampliar su distribución en el país.

\section{Revisión del género Neominniza (Pseudoscorpiones: Garypinidae)}

\author{
Andrés O. Porta ${ }^{1}$, Jaime Pizarro-Araya ${ }^{2}$ \\ ${ }^{1}$ Museo Argentino de Ciencias Naturales "Bernardino Rivadavia"- CONICET, Argentina. hugporta@yahoo.com.ar \\ ${ }^{2}$ Laboratorio de Entomología Ecológica, Departamento de Biología, Facultad de Ciencias, Universidad de La Serena, Chile. \\ japizarro@userena.cl
}


El género Neominniza Beier 1930 se separa del resto de los de la familia Garypinidae por poseer dos pares de ojos, por no tener el arolio dividido, por la posición de las tricobotrias del dedo móvil del pedipalpo y por la forma de la quela. Consta actualmente de dos species con distribución restringida a Chile Neominniza divisa Beier, 1930 y Neominniza halophila Beier 1964. En este trabajo se revisa el género, se presentan 4 especies nuevas de Argentina y de Chile, se ilustra por primera vez la genitalia de los machos y las hembras y se discute la relación con el género Thaumatolpium Beier, 1931. La presentación se ilustra con fotos de microscopia óptica y electrónica y dibujos de las especies consideradas.

\title{
ACAROLOGía
}

\section{Ácaros predadores en las flores de la vegetación espontánea hospedante de Thripidae (Thysanoptera) en el Cinturón Hortícola Platense}

\author{
Paola Carrizo $^{1}$, Marisa Regonat ${ }^{1,2}$ \\ ${ }^{1}$ Universidad de Buenos Aires. Facultad de Agronomía. Departamento Producción Vegetal. Cátedra de Zoología agrícola. Ciudad \\ Autónoma de Buenos Aires, Argentina. pcarrizo@agro.uba.ar \\ ${ }^{2}$ Servicio Nacional de Sanidad y Calidad Agroalimentaria. Dirección del Laboratorio Vegetal. Departamento de Entomología y \\ Acarología. Ciudad Autónoma de Buenos Aires, Argentina. \\ mregonat@senasa.gov.ar
}

En la producción hortícola, la vegetación espontánea puede actuar como un hábitat alternativo tanto para las plagas como para sus enemigos naturales. Entre las plagas más relevantes se hallan los trips vectores del virus de la peste negra, con varios cientos de hospedantes entre plantas cultivadas y malezas. En el Cinturón Hortícola Platense (CHP), Buenos Aires, se realizaron muestreos en 26 especies de plantas hospedantes de trips para determinar la presencia de ácaros depredadores que pudieran contribuir a su control. A través de las cuatro estaciones del año se tomaron muestras en tres sitios del CHP: EE Gorina, EE Hirschorn y una quinta comercial a $1 \mathrm{~km}$. de la Estación Pereyra (Ferrocarril Roca). La muestra estuvo conformada por 25 flores/inflorescencias/especie de planta. Durante tres años de muestreo -60 fechas- se obtuvieron 511 muestras, sumando un total de 14.636 flores/inflorescencias. Las capturas de ácaros ocurrieron entre septiembre y abril, en 23 de las 26 especies de plantas y, particularmente para el mes de enero, en 15 de las 20 especies en flor. Los ejemplares colectados se montaron en solución de Hoyer y los preparados microscópicos obtenidos fueron secados sobre placa térmica $\left(40^{\circ} \mathrm{C}\right.$ por 4 días). Para las determinaciones se utilizaron claves taxonómicas disponibles y microscopio óptico Zeiss Axio Imager.A2 (DIC). Se hallaron representantes de familias de hábitos depredadores: 5 especies de Phytoseiidae -en 8 
especies de plantas- y Erythraeidae (Balaustium sp.) -en 6 especies de plantas-. Asimismo, se encontraron ácaros fitófagos de Tetranychidae (Bryobia sp.) y Tydeidae (Tydeus sp.), ácaros micófagos de la familia Acaridae y oribátidos. Estos resultados aportan al conocimiento de la diversidad de los ácaros depredadores asociados a las plantas hospedantes de trips. El estudio continúa a fin de lograr la determinación de las especies, particularmente de la familia Phytoseiidae.

\title{
Los ácaros como fuente de alimento de anfibios en la Reserva El Destino, Pdo. de Magdalena, Prov. de Buenos Aires, Argentina
}

\author{
Luis A. Giambelluca ${ }^{1}$, Claudia Cédola ${ }^{1}$, Ana Salazar Martinez ${ }^{2}$ \\ ${ }^{1}$ Centro de Estudios Parasitológicos y de Vectores (CONICET CCT La Plata), Argentina. giambelluca@cepave.edu.ar ; \\ claudia.cedola@gmail.com \\ ${ }^{2}$ División Entomología, Facultad de Ciencias Naturales y Museo, Universidad Nacional de La Plata, Argentina. \\ aesamar@hotmail.com
}

Si bien se ha abordado el análisis de la dieta de anfibios en Argentina, no hay trabajos que hayan focalizado en la relación trófica entre estos y los ácaros del suelo. El objetivo de este trabajo fue relevar la acarofauna asociada a la dieta del ensamble de anfibios presentes en La Reserva El Destino con el fin de conocer la relevancia de los ácaros como fuente de alimento. Esta reserva se encuentra emplazada en el partido de Magdalena, Provincia de Buenos Aires, Argentina, protege a ecosistemas como talares, pastizales pampeanos y a la ribera del Río de La Plata. Los muestreos se realizaron en los ambientes de Ribera, Pastizal y Talar. Cada ambiente fue prospectado con un muestreo en otoño y primavera, durante dos años. Por ambiente se eligieron tres sitios. En cada uno de ellos se colocaron 10 trampas Pitfall en línea recta por 7 días. Los anfibios capturados fueron fijados con alcohol 96\%, disectados bajo lupa binocular y se aislaron los ácaros presentes en el contenido estomacal. Los ácaros fueron aclarados, observados en porta objetos excavados o montados en líquido de Hoyer para su adecuada determinación. Se analizaron en total 80 anfibios pertenecientes a Bufonidae (22), Leptodactilidae (31) Hylidae (5) y Odontophrynidae (22), de los cuales 24, 30\% de los ejemplares prospectados, presentaban ácaros (órdenes Oribatida, Mesostigmata y Prostigmata) en su contenido estomacal. Este trabajo constituye el primer registro de ácaros en el contenido estomacal de anfibios en la Reserva de El Destino y visibiliza parte del ensamble de ácaros presente en el pastizal y el talar de esta reserva. 


\title{
Análisis morfométrico del ácaro Laelaps paulistanensis (Mesostigmata, Laelapidae, Laelapinae) parásito de Oligoryzomys nigripes y Oligoryzomys flavescens (Rodentia, Cricetidae, Sigmodontinae) en localidades de la Cuenca del Plata, Argentina
}

\author{
Ekaterina Savchenko ${ }^{1}$, Carlos Galliari ${ }^{1}$, Ulyses F. J. Pardiñas ${ }^{2}$, Marcela Lareschi ${ }^{1}$ \\ ${ }^{1}$ Centro de Estudios Parasitológicos y de Vectores, CEPAVE (CONICET-UNLP), Facultad de Ciencias Naturales y Museo, \\ Universidad Nacional de La Plata. ekaterina@cepave.edu.ar, cailogalliari@gmail.com, mlareschi@cepave.edu.ar \\ ${ }^{2}$ Instituto de Diversidad y Evolución Austral (CCT CONICET-CENPAT), Argentina. ulyses@cenpat-conicet.gob.ar,
}

La familia Laelapidae abarca especies de ectoparásitos de micromamíferos cuya especificidad no está totalmente esclarecida, quizá debido a la presencia de especies crípticas difíciles de identificar mediante métodos convencionales. Ejemplares de Laelaps paulistanensis (Fonseca) fueron registrados desde Venezuela hasta el centro de la Argentina, asociados típicamente a roedores de la tribu Oryzomyini (Cricetidae, Sigmodontinae). Con el fin de explorar la posible presencia de diferentes morfos de L. paulistanensis y analizar si cada uno de estos se asocia a la especie hospedadora y/o si la especie presenta un gradiente geográfico, se estudiaron 50 ejemplares parásitos de los roedores Oligoryzomys flavescens y Oligoryzomys nigripes en 12 localidades. Los ácaros fueron fijados en alcohol 96\%, aclarados en lactofenol y montados en el medio de Hoyer para su estudio al microscopio óptico. Se realizó un análisis de componentes principales sobre 41 medidas seleccionadas del gnatosoma, patas, placas dorsal, esternal, epiginal y anal utilizando el software Statistica y Past. Complementariamente, se aplicaron técnicas de morfometría geométrica (software MorphoJ) sobre 10 landmarks establecidos en la placa epiginal. Los resultados no mostraron diferencias significativas entre las especies hospedadoras. Se evidenció un gradiente geográfico de los rasgos fenotípicos relacionados con el tamaño de la placa dorsal y la quetotaxia y forma de la placa epiginal. Los ácaros del sur (localidades de las provincias de Buenos Aires y Entre Ríos) fueron más pequeños y mostraron una mayor distancia entre las setas epiginales $J v 2$ que los del norte (provincias de Misiones, Formosa y Chaco, noroeste de Corrientes), mientras que los del tercer grupo (Esteros del Iberá en Corrientes) combinaron las características de los otros dos grupos. Futuros estudios de marcadores moleculares podrían aportar a dilucidar si $L$. paulistanensis es un complejo de especies crípticas o una única especie con variación clinal. 


\title{
Estudio comparativo preliminar de riqueza específica y abundancia relativa de ácaros en vegetación espontánea de sistemas hortícolas del Alto Valle de Río Negro y Neuquén
}

\author{
Claudia Cédola ${ }^{1}$, María F. López Armengol ${ }^{2,3}$, Adela Bernardis ${ }^{4}$, Cecilia Gittins López ${ }^{2}$ \\ ${ }^{1}$ CEPAVE, Facultad de Ciencias Naturales y Museo, Universidad Nacional de La Plata - CONICET \\ ${ }^{2}$ INTA-Instituto de Investigación y Desarrollo Tecnológico para la Agricultura Familiar Región Patagonia \\ ${ }^{3}$ Facultad de Ciencias Agrarias, Universidad Nacional del Comahue. CONICET. m.lopezarmengol@conicet.gov.ar \\ ${ }^{4}$ Facultad de Ciencias del Ambiente y la Salud, UNCo.
}

El Alto Valle de Río Negro y Neuquén se desarrolla sobre las cuencas de los ríos Limay, Neuquén y Río Negro. A lo largo de $200 \mathrm{~km}$ del valle, se disponen alternadamente centros urbanos, periurbanos y áreas rurales. Los modelos productivos en la zona (frutícola y hortícola) son altamente dependientes de insumos externos, y la aplicación de Buenas Prácticas Agrícolas requiere del conocimiento sobre la diversidad de plagas y benéficos. Los ácaros constituyen un grupo de arácnidos ubicuos y con reconocidas funciones ecológicas en los agroecosistemas. Por lo expuesto, el objetivo del presente estudio fue comparar la riqueza específica, abundancia relativa de depredadores en sistemas hortícolas periurbano y rural en el Alto Valle de Río Negro y Neuquén. El muestreo se realizó en Plottier (Neuquén), predio periurbano y en Campo Grande (Río Negro), predio rural. En ambas localidades se estudiaron parches de vegetación espontánea en: zona operativa, cortina rompevientos con álamos y monte frutal abandonado (peral). Se colocaron trampas "pitfall", recolectadas mensualmente desde enero-marzo de 2017. Se capturaron 87 individuos pertenecientes a 18 especies y 9 familias, siendo las más representativas Erythraediae (5 especies), Bdellidae (4 especie), Anystidae (3 especies) y Stigmaeidae ( 2 especies). Las especies exclusivas de Campo Grande fueron 11/18 y en Plottier $2 / 18$. Ambas localidades compartieron 5/18. La mayor abundancia y riqueza específica fue observada en Campo Grande (93\% y 16/18, respectivamente). Los parches de vegetación espontánea que presentaron mayor abundancia fueron el monte frutal y zona operativa de Campo Grande. En la zona operativa Cynodon dactylon (L.) Pers., Melilothus albus Medik., Sorghum halepense (L.) Pers. y Tessaria sp. presentaron más del $80 \%$ de cobertura. A partir de los resultados obtenidos se puede concluir que estas especies vegetales pueden poseer potencial interés para establecer infraestructuras ecológicas con el fin de propiciar la permanencia de los ácaros depredadores. 


\title{
ECOLOGÍA
}

\section{Resultados preliminares del relevamiento de las arañas (Arachnida, Araneae) de la Reserva Natural Hídrica de Villa Gobernador Gálvez (Santa Fe, Argentina)}

\author{
M. Florencia Ansaldi ${ }^{1}$, Luciano Peralta ${ }^{2}$ \\ ${ }^{1}$ Facultad de Ciencias Agrarias, Universidad Nacional de Rosario, Argentina. ansaldiflo@gmail.com \\ ${ }^{2}$ Laboratorio de Ecología, Instituto de Investigaciones Marinas y Costeras (IIMyC; CONICET-UNMDP). Universidad \\ Nacional de Mar del Plata, Argentina. luccianoperalta@hotmail.com
}

La Reserva Natural Hídrica de Villa Gobernador Gálvez (Santa Fe, Argentina), está ubicada en las márgenes del arroyo Saladillo ( $33^{\circ} 00^{\prime} 35^{\prime \prime} \mathrm{S} 60^{\circ} 37^{\prime} 37^{\prime \prime} \mathrm{O}$ ), en el límite con la ciudad de Rosario, a sólo $2 \mathrm{~km}$ del río Paraná. Comprende más de 100 hectáreas, donde el estrato arbóreo está conformado mayormente por especies típicas del espinal, con algunos pocos parches de exóticas. Las herbáceas son representativas de la flora pampeana casi inexistentes en la región a causa de la agriculturización. Esta reserva representa un relicto de biodiversidad, donde confluyen las ecorregiones del espinal, pastizal pampeano y parte del delta del Paraná. Esto la convierte en un sitio prioritario para el estudio y preservación de su flora y fauna. Así mismo, las arañas comprenden un grupo faunístico diverso con un alto potencial como bioindicado res del estado de conservación ambiental. Nuestro objetivo es relevar la diversidad de arañas de la reserva para contribuir a su conservación. En las campañas, realizadas entre julio de 2016 y julio de 2018, se utilizaron trampas de caída, paraguas entomológico y colecta manual. Los ejemplares fueron conservados en alcohol al $80 \%$ e identificados hasta el nivel de especie/morfoespecie, mediante el uso de claves específicas y descripciones originales para cada caso. Se colectaron un total de 297 arañas pertenecientes a 24 familias y 82 especies/morfoespecies. Mediante colecta manual y paraguas entomológico se recolectaron 233 ejemplares correspondientes a 64 especies/morfoespecies; con trampas de caída se obtuvieron 64 ejemplares correspondientes a 27 especies/morfoespecies. De estos resultados preliminares se destacan una posible especie nueva de Trachelopachys y los primeros registros para Santa Fe de Actinopus longipalpis y Homoeomma uruguayense. Se espera que la riqueza y los registros novedosos aumenten considerablemente. La diversidad de arañas de la reserva actualmente presenta un buen estado de conservación, extrapolable a una diversidad biológica muy importante para preservar. 


\title{
Análisis de la composición de especies de arañas (Arachnida, Araneae) en el paisaje urbano de la ciudad de Córdoba, Argentina
}

\author{
Carina I. Argañaraz ${ }^{1}$, Raquel M. Gleiser ${ }^{1,2}$ \\ ${ }^{1}$ Centro de Relevamiento y Evaluación de Recursos Agrícolas y Naturales. Instituto Multidisciplinario de Biología Vegetal. \\ Universidad Nacional de Córdoba- CONICET. Argentina. c.arg.bio@gmail.com \\ ${ }^{2}$ Cátedra de Ecología, Facultad de Ciencias Exactas, Físicas y Naturales, Universidad Nacional de Córdoba, Argentina. \\ raquel.gleiser@unc.edu.ar
}

Un enfoque para estudiar el efecto del paisaje urbano sobre la biodiversidad que habita en las ciudades es considerar a la urbanización como un agente de disturbio. Las respuestas al disturbio pueden ser variadas entre taxones. En las arañas no siempre se han encontrado efectos en la riqueza de especies, lo que suele atribuirse a respuestas diferenciales y complementarias entre grupos de especialistas y generalistas, relacionadas a la intensidad de urbanización (disturbio). Analizamos el cambio en la composición de especies de arañas presentes en espacios verdes de la ciudad de Córdoba, en dos condiciones de intensidad de urbanización. Se consideraron nueve sitios ubicados en la periferia de la ciudad (ambiente de bajo disturbio) y 11 sitios en el centro urbano (ambiente de alto disturbio). Se tomaron 40 muestras en dos años consecutivos con un aspirador/soplador G-VAC. Los individuos adultos se determinaron a nivel de especie y morfoespecies. Se compararon las condiciones mediante análisis de similitud de SØrensen y NMDS seguido de PERMANOVA y SIMPER. Se identificaron 87 especies/morfoespecies. El índice de SØrensen indicó un 30\% de disimilitud entre ambas comunidades en cuanto a las especies presentes y sólo un $20 \%$ considerando sus abundancias relativas. Gráficamente mediante NMDS, se observó el mismo resultado, dos grupos parcialmente solapados (PERMANOVA, $\mathrm{p}<0,007$ ). De 87, 12 especies explicaron el $60 \%$ de la disimilitud entre ambos ambientes (SIMPER). En conclusión, los resultados no muestran una evidente diferencia en composición de especies entre espacios verdes en contextos de mayor o menor intensidad de disturbio urbano, y si bien en el ambiente de menor disturbio se detectaron especies exclusivas (30), la mayor disimilitud fue otorgada por las abundancias de las especies más pioneras.

\section{Diversidad de arañas (Araneae) en la Reserva Natural Urbana "Cueva de los Leones", Bahía Blanca, Provincia de Buenos Aires}

\author{
Melisa Ayoroa, Mariana G. Mancini, Agustín J. Chiovetta, Carolina B. Guerra, Micaela Nicoletta, \\ Justina Panchuk
}

\footnotetext{
Departamento de Biología, Bioquímica y Farmacia, Universidad Nacional del Sur, Bahía Blanca, Argentina. melisaayoroa@hotmail.com; mariana.mancini15@gmail.com; agus.chio93@gmail.com; caro.guerra@hotmail.com.ar; mmnicolettal@gmail.com; justina.p@outlook.com
} 
La reserva natural urbana Cueva de los Leones se ubica en el periurbano norte de la ciudad de Bahía Blanca, provincia de Buenos Aires. El área cuenta con 30 ha de superficie y se enc uentra sobre depósitos sedimentarios limo-arenosos que culminan con un nivel de tosca. El sitio constituye un verdadero ecotono con vegetación característica de las provincias fitogeográficas Pampeana, Espinal, Monte y Patagónica. El presente trabajo tiene como finalidad conocer la diversidad de arañas en dicha área a través de un estudio de relevamiento. Dentro de los objetivos, se pretende realizar la primera lista de familias de arañas y comparar su diversidad en dos sitios con diferente geomorfología y composición vegetacional: Valle Menor (VM) (densidad alta de herbáceas) y Llanura Sedimentaria (LS) (densidad media de herbáceas, densidad media de arbustivas y densidad alta de arbóreas). Se realizaron cuatro colectas estacionales (junio de 2017- abril de 2018). Se utilizaron diferentes técnicas: pitfalls (trampas de caída), red entomológica y colecta manual diurna. Los datos climáticos se obtuvieron de estaciones meteorológicas en cercanías al área de estudio. En total se capturaron 736 arañas pertenecientes a 25 familias. No se encontraron diferencias significativas en la abundancia de arañas entre las estaciones $(\mathrm{F}=6,33, \mathrm{p}=0,08)$ como así tampoco entre los sitios $(\mathrm{F}=0,95, \mathrm{p}=0,4)$. Sin embargo se observó que el sitio VM presentó una mayor abundancia con respecto al sitio LS. Ambos sitios presentaron índices de diversidad similares.

\title{
Descripción preliminar de los ensambles de familias de arañas epigeas como indicadores del estado de conservación de ambientes agrícolas y ganaderos del Chaco Húmedo (Santa Fe)
}

\author{
Caterina Barisón ${ }^{1}$, M. Florencia Ansaldi ${ }^{2}$, Luciano Peralta ${ }^{3}$, Ignacio M. Barberis ${ }^{1}$, José L. Vesprini ${ }^{1}$ \\ ${ }^{1}$ Instituto de Investigaciones en Ciencias Agrarias de Rosario (IICAR; UNR-CONICET). Facultad de Ciencias Agrarias, \\ Universidad Nacional de Rosario, Argentina. catebarison@gmail.com; ignaciobarberis@yahoo.com; jvesprin@unr.edu.ar \\ ${ }^{2}$ Facultad de Ciencias Agrarias, Universidad Nacional de Rosario, Argentina. ansaldiflo@gmail.com \\ ${ }^{3}$ Laboratorio de Ecología, Instituto de Investigaciones Marinas y Costeras (IIMyC; CONICET-UNMDP). Universidad Nacional de \\ Mar del Plata, Argentina. luccianoperalta@hotmail.com
}

El uso de la tierra ha transformado una larga proporción de la superficie del planeta principalmente por medio de la deforestación de bosques y las prácticas agrícolas-ganaderas. Resultando en la adquisición de recursos naturales para necesidades humanas a expensas de la degradación de ambientes nativos. El Chaco Húmedo es una región que abarca aproximadamente 12.000.000 ha en Argentina. Ocupa la mitad oriental de las provincias de Chaco y Formosa, y parte del norte de Santa Fe. Los bosques del Chaco Húmedo santafesino ("la Cuña Boscosa santafesina") presentan una notable heterogeneidad estructural y florística. En los últimos años se ha registrado un aumento en la tasa de deforestación de esta región debido a la expansión de la frontera agrícola-ganadera. Las arañas conforman uno de los grupos más abundantes y diversos de los ecosistemas terrestres, presentan gran potencial como indicador de biodiversidad y el estado de conservación ambiental. Aquellas familias de arañas edáficas más activas, como Lycosidae, Gnaphosidae y Linyphiidae incrementan su dominancia 
en sitios disturbados. Este trabajo tuvo como objetivo estudiar los ensambles de arañas epigeas como indicadores del estado de conservación de ambientes agrícolas y ganaderos de la región. Para ello, se seleccionaron 10 fragmentos boscosos representativos del quebrachal chaqueño, cinco de ellos insertos en ambientes ganaderos y cinco insertos en una matriz agrícola. Durante la primavera de 2017 se capturaron arañas mediante trampas pitfall, las cuales permanecieron activas durante cinco días. Los resultados preliminares arrojaron un total de 885 ejemplares pertenecientes a 22 familias. Las familias más abundantes en los sitios ganaderos fueron Lycosidae (48,75\%), Linyphiidae (35,23\%) y Gnaphosidae $(2,49 \%)$. De manera similar, en los sitios agrícolas abundaron Lycosidae (63,82\%), Linyphiidae $(22,04 \%)$ y Gnaphosidae $(1,97 \%)$. Las restantes familias tuvieron una representación muy baja en ambos sectores. Estos resultados podrían alertar acerca del severo impacto antrópico que presentaría esta región.

\title{
Análisis de Olsmtead-Tukey de una comunidad de arañas en un cultivo de alcaucil perteneciente al Cinturón Hortícola Platense (Buenos Aires, Argentina)
}

\author{
Cecilia S. Gabellone, Pablo Addamo, Marcela I. Schneider, Alda González
}

\begin{abstract}
Centro de Estudios Parasitológicos y de Vectores (CEPAVE) (CONICET-UNLP). Facultad de Ciencias Naturales y Museo, Universidad Nacional de La Plata, Argentina. csgabellone@cepave.edu.ar, pabloaddamo@gmail.com, mschneider@cepave.edu.ar, asgonzalez@cepave.edu.ar
\end{abstract}

La biodiversidad está influenciada por los cambios físicos del ambiente como un resultado de las actividades humanas. Lo mismo ocurre en los sistemas hortícolas, con el uso desmedido de agroquímicos. Dentro de estos, el Cinturón Hortícola Platense es una de las principales regiones productivas del país, en la cual, el alcaucil es de gran importancia debido a su auge a nivel regional y nacional. Las comunidades de arañas son componentes estructurales muy importantes en los ecosistemas. El reconocimiento de estas comunidades facilita el seguimiento de procesos de regeneración natural en áreas sometidas a diferentes alteraciones antropogénicas. Se realizaron muestreos estacionales en la zona de Los Hornos, en dos cultivos de diferente edad. Se utilizó G-Vac (garden-vaccum) y trampas de caída (pitfall). Durante 2 años, se tomaron por estación 40 muestras con cada uno de los métodos señalados, haciendo un total de 640 muestras. Los ejemplares colectados se separaron, determinaron y conservaron en alcohol 96\%. Para el análisis se realizó el método de Olmstead-Tukey, el cual permite clasificar en cuadrantes a las especies de arañas según su abundancia y prevalencia. Los cuadrantes están definidos por las especies dominantes, comunes, ocasionales y raras. En el eje de las abscisas se grafica el logaritmo de la abundancia de cada especie y en el eje de las ordenadas el porcentaje de la frecuencia de aparición. El total de arañas colectadas fue de 2700 ejemplares, incluidos en 18 familias, 50 géneros, 43 especies identificadas y 7 morfoespecies. Se consideraron las abundancias totales en cada fecha de muestreo. Alopecosa moesta se encontró en todos los censos, Glenognatha lacteovittata fue muy frecuente y con una 
densidad semejante, mientras que Laminacauda montevidensis tuvo la mayor densidad, encontrándose en el $64 \%$ de los censos. Las familias representadas por bajo número y frecuencia fueron Anyphaenidae, Araneidae y Theridiidae.

\title{
Relevamiento de la araneofauna en pastizales afectados por incendios en la Reserva Natural de Punta Lara
}

\author{
Luis Giambelluca, Andrea Armendano, Sandra González, Sergio Rodríguez Gil, Guillermo \\ Reboredo, Cecilia Gabellone, Pablo Addamo, Nicolás Lischetti, Kevin Pons, Dolores Goñi, Flavia \\ Cassinelli, Alda González
Centro de Estudios Parasitológicos y de Vectores (CEPAVE) (CONICET-UNLP). Facultad de Ciencias Naturales y Museo, Universidad Nacional de La Plata, Argentina. giambelluca@cepave.edu.ar, aarmendano@hotmail.com, san.gonzalez.san@gmail.com, sergio.rodriguezgil@gmail.com,grreboredo@yahoo.com.ar, csgabellone@cepave.edu.ar, pabloaddamo@gmail.com, lischettinicolas@fcnym.unlp,ponskevin@fcnym.unlp.edu.ar, doloresm.g@hotmail.com, \\ fla.cassinelli@gmail.com, asgonzalez@cepave.edu.ar.
}

La Reserva Natural de Punta Lara está situada sobre la costa del Río de La Plata ( $34^{\circ} 47^{\prime} 27.96^{\prime \prime}$ S, $57^{\circ} 59^{\prime} 48.84^{\prime \prime} \mathrm{W}$ ), en el noreste de la Provincia de Buenos Aires. Cuenta con una superficie de unas 6000 ha. y presenta distintos ambientes, entre ellos selva marginal, pajonal y pastizal. En enero de 2018 la zona de pastizal fue afectada por un incendio de proporciones considerables, que abarcó unas 560ha. y persistió durante un mes. El objetivo del trabajo consistió en analizar la comunidad de arañas del pastizal quemado y otra zona adyacente no afectada por el fuego (control). La recolección de los ejemplares se realizó mediante G-Vac (Garden Vaccum) y trampas de caída (pitfall) un mes después del incendio. Se tomaron un total de 40 muestras, 20 en la zona quemada y 20 en la zona control. Se analizó la composición de familias, riqueza y abundancia relativa de arañas para las dos zonas. Se registró un total de 136 arañas pertenecientes a 10 familias, de las cuales la más abundante fue Lycosidae (41,18\%), seguida por Salticidae $(13,97 \%)$ y Thomisidae $(11,76 \%)$. El resto de las familias reg istradas no superó el $10 \%$ de abundancia relativa. Respecto a los controles mostraron diferencias significativas, registrándose un total de 328 arañas representadas por 11 familias. Mediante las trampas de caída solo se registraron 3 familias (Ctenidae, Linyphiidae y Lycosidae) respecto a la zona no quemada que registró 6 familias. La composición de familias fue similar en ambas áreas, con excepción de Trachelidae representada por la especie Meriola cetiformis, siendo la única que no se encontró en la zona quemada, sugiriendo una rápida recolonización del área afectada. 


\title{
Riqueza, composición y distribución de escorpiones (Orden Scorpiones) en las ecorregiones de Paraguay, basados en especímenes pertenecientes a dos colecciones zoológicas
}

\author{
David J. Guerrero ${ }^{1}$, Ignacio Ávila ${ }^{1}$, John A. Kochalka ${ }^{2}$ \\ ${ }^{1}$ Universidad Nacional de Asunción, Facultad de Ciencias Exactas y Naturales, Departamento de Biología, Programa de Iniciación \\ Científica. San Lorenzo, Departamento Central, Paraguay. megadavidjgo@hotmail.com, riavilat@gmail.com \\ ${ }^{2}$ Museo Nacional de Historia Natural del Paraguay. San Lorenzo, Departamento Central, Paraguay. johnkochalka@gmail.com.
}

Los escorpiones constituyen modelos biológicos útiles para análisis ecológicos y biogeográficos en bosques neotropicales. En este trabajo se analiza la riqueza, composición y distribución geográfica de los escorpiones del Paraguay basados en especímenes pertenecientes a dos colecciones zoológicas. Con los datos obtenidos se elaboraron: una matriz de incidencia por ecorregión indicando la presencia de las especies, mapas de distribución e índices de Jacard y Sorensen para estimar la similitud de la fauna de escorpiones por ecorregión. Como resultado se encontraron 15 especies de escorpiones en Paraguay, con Bothriurus sp.1 y Ananteris sp. 1 como posibles nuevos registros para el país. La riqueza de cada ecorregión fue: Chaco Húmedo (12), Bosque Atlántico del Alto Paraná (8), Chaco Seco (4), Cerrado (2) y Pantanal (1). Las ecorregiones con mayor similitud de composición fueron el Chaco Húmedo y el Bosque Atlántico del Alto Paraná. Es posible que estos resultados puedan estar sesgados por el esfuerzo de muestreo dispar, también se debe contrastar con otras investigaciones la matriz de incidencia de las especies para conocer mejor su presencia en las ecorregiones. Este trabajo presenta una lista actualizada de las especies de escorpiones del Paraguay, así mismo se recomienda hacer más muestreos en todo el país para conocer a profundidad la ecología y biogeografía de estos arácnidos.

\section{Sobre la alimentación de Tityus trivittatus (Scorpiones: Buthidae)}

Iván A. López, Juan Kopp, Mónica S. Iglesias

\footnotetext{
Laboratorio de Artrópodos. Departamento de Biodiversidad y Biología Experimental. Facultad de Ciencias Exactas y Naturales, Universidad de Buenos Aires. Ciudad Autónoma de Buenos Aires, Argentina. E-mail: ivann.alejandrolopez@gmail.com; koppjuan@gmail.com; iglesias.fcen@gmail.com
}

Los escorpiones son depredadores, con un amplio espectro de presas. Tityus trivittatus (Buthidae), es un escorpión de interés sanitario, con distribución en el centro y norte de Argentina. Nuestro objetivo fue determinar si el tipo de presa, la relación de peso (predador/presa) y la temperatura influyen en la alimentación de Tityus trivittatus. Para ello, a 14 escorpiones se les ofreció un tipo de presa por vez (Gryllus assimilis, Forficula sp. y Blattella germanica), a $23 \pm 2^{\circ} \mathrm{C}$ y luego a $15 \pm 2^{\circ} \mathrm{C}$. Previamente y entre tandas de alimentación 
los escorpiones se sometieron a ayuno durante siete días. En cada experiencia se introdujeron depredador y presa en un recipiente, se registró si se alimentaba durante los primeros 10' y de no ocurrir, se los dejó durante 24hs. Pasado este tiempo se observó si el predador se alimentó. Se realizaron 2 modelos (logísticos) generalizados mixtos con la variable respuesta comió o no comió $\left(10^{\prime}+24 \mathrm{hs}\right.$ y $\left.24 \mathrm{hs}\right)$, las variables explicativas fueron tipo de presa, relación de pesos depredador/presa y temperatura. Se utilizaron paquetes estadísticos con entorno en R. El tipo de presas fue significativo en ambos modelos, con preferencia por los grillos cuando la variable respuesta fue comió en general $\left(10^{\prime}+24 \mathrm{hs}\right)$ y cucarachas cuando la variable respuesta fue comió solo luego de $24 \mathrm{hs}$. En ambos casos los escorpiones prefirieron grillos y cucarachas antes que dermápteros. La temperatura influyó en la respuesta comió $\left(10^{`}+24 \mathrm{hs}\right)$, pero no así en comió solo después de $24 \mathrm{hs}$. La relación de tamaño no fue significativa. Los resultados indican que el tipo de presa influye en la alimentación del escorpión, con preferencia por grillos (sobre todo los primeros 10') y cucarachas (si se las dejaba 24hs). Además las temperaturas altas aumentarían el comportamiento de depredación de T. trivittatus en los primeros 10' a partir del encuentro.

\title{
Análisis preliminar de los ensambles de arañas Salticidae en áreas protegidas y antropizadas del Chaco Húmedo
}

\author{
María F. Nadal ${ }^{1}$, Gonzalo D. Rubio ${ }^{2}$, Gilberto Avalos ${ }^{1}$ \\ ${ }^{1}$ Laboratorio de Biología de los Artrópodos, Facultad de Ciencias Exactas y Naturales y Agrimensura, Universidad Nacional del \\ Nordeste, Argentina. florencia.nadal@gmail.com, gilbertoa@exa.unne.edu.ar \\ ${ }^{2}$ CONICET, Estación Experimental Agropecuaria Cerro Azul, Instituto Nacional de Tecnología Agropecuaria, Argentina. \\ grubio@conicet.gov.ar
}

El Gran Chaco es un área clave para la conservación, sin embargo el uso no planificado de sus recursos peligra gran parte de su diversidad biológica. En esta investigación se pretende estudiar la diversidad de arañas Salticidae y evaluar su potencialidad como indicadoras de calidad ambiental en dos ambientes protegidos y dos áreas con cierto grado de antropización del Chaco Húmedo. Los muestreos se llevan a cabo en el Parque Nacional Chaco (PNC) $\left(26^{\circ} 47^{\prime} 20^{\prime \prime} \mathrm{S}, 59^{\circ} 36^{\prime} 44^{\prime \prime} \mathrm{O}\right)$, el Parque Provincial Pampa del Indio (PPI) $\left(26^{\circ}\right.$

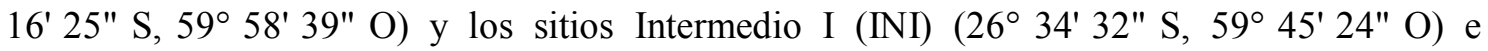

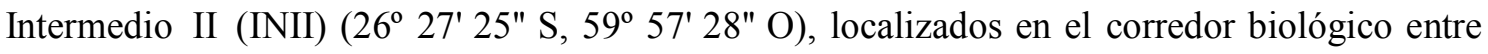
ambos parques. En cada lugar se seleccionan bosques y pastizales, en los que se trazan transectas de $200 \times 2 \mathrm{~m}$. En ellas se recolectan las arañas en cinco puntos a través de las técnicas: golpeteo de follaje y tamizado en hojarasca en los bosques, aspirado en los pastizales, y captura directa en ambos ambientes. Con los especímenes cuantificados e identificados hasta el momento, se hicieron análisis estadísticos preliminares con el programa PAST Versión 2.16. Se recolectaron en total 1971 arañas Salticidae y se identificaron 69 especies. La abundancia fue mayor en el INII ( $\mathrm{N}=373)$, seguida por el INI $(\mathrm{N}=322)$. La riqueza fue superior en el PNC y en el INII. La diversidad (H') fue mayor en el INII, seguida por el PNC. La equidad (J') fue 
mayor en el INII y los valores de dominancia (D) fueron mayores en los parques (Los análisis de la diversidad beta mostraron una menor similitud entre el INII y el PNC (30\%, BrayCurtis y Jaccard) y una mayor similitud entre el PPI y el INI (45\%, Jaccard) y entre el INI y el INII (46\%, Bray-curtis).

\title{
Cambios en la composición de especies y rasgos funcionales de arañas en respuesta al uso de la tierra
}

\author{
Carolina M. Pinto, M. Isabel Bellocq, Julieta Filloy
}

Dep. Ecología, Genética y Evolución, UBA, Argentina - IEGEBA, CONICET, Buenos Aires, Argentina. carolinap90@gmail.com,
bellocq@ege.fcen.uba.ar, jfilloy@ege.fcen.uba.ar

Los usos de la tierra asociados a las actividades humanas transforman el hábitat provocando cambios taxonómicos y funcionales en los ensambles de especies. El objetivo fue examinar la influencia en la composición taxonómica y funcional del ensamble de arañas de los principales usos de la tierra en la pampa mesopotámica. Se seleccionaron 5 cultivos de soja, 5 campos ganaderos, 5 plantaciones maduras de Eucalipto y 5 de pastizal natural en Entre Ríos. En cada sitio se colocaron trampas de caída y se realizaron aspiradas de un minuto en primavera-verano. Se estimó la magnitud del cambio en la composición de especies y rasgos de arañas en usos respecto al pastizal natural y la disimilitud taxonómica y funcional entre usos y áreas naturales. Para identificar qué especies contribuyen principalmente a la disimilitud taxonómica se hizo un análisis de porcentajes de similitud (SIMPER). Se identificaron los rasgos asociados a cada uso mediante un análisis de 4 esquinas. La disimilitud taxonómica respecto al pastizal fue alta y no varió entre usos. La especie que más contribuyó a la disimilitud en cultivosfue Steatoda ancorata; en plantaciones Apopyllus silvestrii; y en campos ganaderos Erigone sp1, previamente reportada en reservas de pastizal. La disimilitud funcional fue mayor en cultivos que en plantaciones y campos ganaderos respectivamente. Las arañas cazadoras en emboscada fueron más abundantes en plantaciones, las cazadoras activas de mayor tamaño se asociaron a campos ganaderos y las arañas nocturnas a pastizales. La composición de arañas fue afectada por los usos de la tierra, con rasgos asociados particularmente a cada uno de ellos excepto los cultivos. La influencia sobre la diversidad funcional, pero no taxonómica, varía entre los usos estudiados. La ganadería es el uso de la tierra que mejor conserva rasgos y especies de arañas de pastizal. 


\title{
Estudio preliminar de recambio de especies del Parque Nacional Chaco y el Parque provincial Pampa del Indio, Chaco, Argentina
}

\author{
Ivo Zanone ${ }^{1}$, Gilberto Avalos', Alda González ${ }^{2}$ \\ ${ }^{1}$ Universidad Nacional del Nordeste, Facultad de Ciencias Exactas y Naturales, Cátedra de 8 Biología de los Artrópodos, Avda. \\ Libertad 5470 (3400) Corrientes, Argentina. ivo.zanone@gmail.com, gilbertoavalos@exa.edu.ar. \\ ${ }^{2}$ Centro de Estudios Parasitológicos y de Vectores (CEPAVE) (CONICET-UNLP), Facultad de Ciencias Naturales y Museo, \\ Universidad Nacional de La Plata, Argentina. asgonzalez@cepave.edu.ar
}

Los estudios de biodiversidad en áreas protegidas son necesarios para definir y aplicar políticas adecuadas de manejo y conservación. Se trabajó en el Parque Nacional Chaco (PN) ubicado en el centro este de la provincia del Chaco $\left(26^{\circ} 48^{\prime} 39.61^{\prime \prime} \mathrm{S}, 59^{\circ} 37^{\prime} 23.63^{\prime \prime} \mathrm{O}\right)$ con un área de 14.981ha, y en el Parque Provincial Pampa del Indio (PP) ubicado en el centro norte de la provincia $\left(26^{\circ} 4^{\prime} 26.97^{\prime \prime} \mathrm{S}, 59^{\circ} 56^{\prime} 35.64^{\prime \prime} \mathrm{O}\right)$ con un área de 8.633 ha. Ambos tienen la finalidad de albergar una porción representativa de la ecorregión del Chaco Húmedo. Se estudió el recambio de especies a lo largo de un gradiente altitudinal desde el parque Chaco hacia Pampa del Indio, tanto en bosques como en pastizales. Se trazaron 3 transectas de $200 \mathrm{~m}$ y se tomaron muestras en cinco puntos separados por $50 \mathrm{~m}$. Se obtuvieron 15 muestras por técnica y lugar. Las técnicas utilizadas fueron golpeteo de follaje en bosques, aspirado con aspiradora de jardín (Mod. $220 \mathrm{~V}$-AR) en pastizales y captura manual directa nocturna y diurna en ambos ambientes. La determinación taxonómica se realizó mediante claves disponibles. Se analizó la diversidad alfa y beta mediante R, utilizando los paquetes iNEXT y adespatial respectivamente. Según el índice de diversidad verdadera, $\mathrm{PN}(\mathrm{D} 0=27,33)$ tiene $35 \%$ más diversidad que PP $(\mathrm{D} 0=17,78)$, pero similares abundancias ( $\mathrm{D} 1=13,38$ y 13,25 respectivamente) en bosque. En pastizal, PP (D0=24,93) fue $34 \%$ más diverso que PN $(\mathrm{D} 0=16,48)$ con casi el doble de abundancia ( $\mathrm{D} 1=8,25$ y 3,58 respectivamente). La diversidad beta dio un recambio en los bosques de un $75 \%$ de especies y en los pastizales de $65 \%$. Las diferencias entre bosques y pastizales probablemente se deban al grado de degradación de los mismos, no obstante, como era de esperarse, se observó un alto recambio de especies a lo largo del gradiente. 


\title{
IMPORTANCIA SANITARIA
}

\section{Toxicidad en restos de telsones de Tityus trivittatus utilizados para la producción de veneno}

\author{
Marcela A. Desio, Jantine H. van Grootheest, Laura C. Lanari, Adolfo R. de Roodt \\ Área Investigación y Desarrollo-Venenos, I.N.P.B. - A.N.L.I.S. “Dr. Carlos G. Malbrán”, Av. Vélez Sarsfield 563, CP 1281, \\ C.A.B.A, Argentina.marcela.madmad@gmail.com, jantinevg@hotmail.com, llanari@anlis.gov.ar, aderoodt@anlis.gov.ar.
}

Tityus trivittatus es el escorpión responsable de la mayor cantidad de accidentes por animales venenosos en Argentina y provoca envenenamientos fatales, especialmente en la población pediátrica. El tratamiento específico para los envenenamientos es el uso de antiveneno, que es producido por el INPB-ANLIS "Dr. Carlos G. Malbrán". Para su producción, la obtención del veneno es fundamental y uno de los métodos para obtenerlo es el homogenato de telsones. Proveedores de diferentes provincias envían al Instituto telsones que se utilizan para diferentes puntos del proceso producción. En ocasiones los telsones enviados presentan restos de material celómico adheridos, en apariencia no perteneciente al telson, por lo que son descartados. Dada la falta de información sobre la toxicidad de estos tejidos, que podrían contener restos glandulares, se realizó sobre restos descartados de 418 telsones el mismo procedimiento utilizado para la extracción de veneno de telsones. El material así obtenido, se analizó por SDS- PAGE, por doble inmunoprecipitación y se determinó su potencia letal. El patrón cromatográfico en condiciones no reductoras, muestra componentes con masas moleculares desde alrededor los $250 \mathrm{kDa}$ hasta los $2 \mathrm{kDa}$, con la presencia de muchos componentes no observados en los patrones correspondientes al veneno ordeñado o los homogenatos de telson. El material obtenido fue reconocido por anti-veneno obtenido por homogenato de telson y por anti-veneno obtenido por estimulación eléctrica, lo que demostró la presencia de veneno en este material. La potencia letal intraperitoneal (dosis mínima mortal) en ratones (CF-1, $20 \mathrm{~g}$ ) fue de $96 \mu \mathrm{g} / \mathrm{g}$. La signología del envenenamiento fue la típica de los envenenamientos causados por T. trivittatus. Si bien este material no parece apto para ensayos de toxicidad dada la gran cantidad de componentes no relacionados con el veneno y su baja toxicidad, podría ser utilizado como una fuente para la purificación de neurotoxinas. 


\title{
Elaboración de Suero Antiloxosceles en el Instituto Biológico "Dr. Tomás Perón"
}

\author{
Cecilia González ${ }^{1,2}$, Pablo Abrahamovich ${ }^{1}$, María F. Pérez ${ }^{1}$, María C. \\ Marchan $^{1}$, Néstor Nicolai ${ }^{1}$ \\ ${ }^{1}$ Departamento de Sueros Hiperinmunes. Instituto Biológico Dr. Tomas Perón, Ministerio de Salud de la Provincia de Buenos Aires, \\ Argentina. \\ ${ }^{2}$ Coordinación de Sueros Antiponzoñosos, Ministerio de Salud de la Provincia de Buenos Aires, Argentina. \\ ceciliago@hotmail.com,pabloabrahamovich@hotmail.com, florenciaperezazqueta@gmail.com, cecimarchan85@gmail.com, \\ nestornicolai@gmail.com
}

En la Provincia de Buenos Aires se encuentran dos especies nativas de arañas de importancia sanitaria debido a la toxicidad de su veneno, Latrodectus mirabilis y Loxosceles laeta, siendo el promedio de accidentes causados por la picadura de estos arácnidos, de 67 casos por año. El Instituto Biológico "Dr. Tomás Perón", dependiente del Ministerio de Salud de la Provincia de Buenos Aires, atendiendo a la potencial letalidad de estos venenos, produce desde el año 1982 el Suero Antilatrodectus para su distribución en toda la provincia. En el año 2017, se inició la producción del Suero Antiloxoscélico, único tratamiento efectivo para casos de loxoscelismo cutáneo y cutáneo-visceral. A partir de la extracción de aparatos glandulares de arañas de la especie Loxosceles laeta, obtenidas a campo y nacidas en cautiverio, mantenidas en bioterio en frascos individuales, fue realizado el homogenato con el que se procedió a la inmunización de equinos suero-dadores. Una vez alcanzado el título de anticuerpos necesario, se realizó la sangría y posterior purificación del suero. El mismo fue sometido a diversos controles de calidad, a fin de evaluar su potencia y efectividad. Se obtuvieron $9850 \mathrm{ml}$. de suero con capacidad neutralizante, que fueron dispensados en 1688 frasco ampollas de $5 \mathrm{ml}$., para ser distribuidos gratuitamente a los Centros Antiponzoñosos de la Provincia de Buenos Aires.

\section{Evaluación de la actividad repelente de aceites esenciales de lavanda y pino y formulación DEET (25\%) sobre Tityus trivittatus Kraepelin, 1898 (Scorpiones, Buthidae)}

\author{
Mariano A. Lenna, Hernán A. Iuri, Mónica S. Iglesias \\ Laboratorio de Artrópodos, Departamento de Biodiversidad y Biología Experimental, Facultad de Ciencias Exactas y \\ Naturales, Universidad de Buenos Aires. Ciudad Autónoma de Buenos Aires. Argentina. \\ marian_lenna@hotmail.com; hernan.augusto.iuri86@gmail.com; iglesias.fcen@gmail.com
}


Tityus trivittatus, de amplia distribución geográfica, es la especie de escorpión de mayor importancia sanitaria en la Argentina. De hábitos urbanos, prefiere lugares oscuros y húmedos como ser galerías subterráneas, oquedades en árboles y paredes, cañerías y sótanos, donde se encuentran protegidos durante el día. En la noche, se encuentran más activos, se los puede observar deambulando y/o predando insectos y otros arácnidos. Los repelentes son una alternativa al insecticida, sobretodo en entornos donde no es conveniente usarlos. El objetivo de este trabajo es evaluar la actividad repelente sobre T. trivittatus en condiciones de laboratorio de una formulación de DEET (N,N-dietil-3-metilbenzamida) al 25\% y aceites esenciales de lavanda y pino. Para ello utilizamos una arena dividida en tres cámaras, una superior y dos inferiores, separadas de la superior por una malla. En una de las cámaras inferiores se colocaron una placa de Petri con la sustancia $(1 \mathrm{ml})$ mientras que en la otra inferior se colocó una placa de Petri sin la sustancia que se quiere testear. Las placas se alternaron de lado en cada ensayo. Se colocaron lotes de 5 escorpiones en el centro de la cámara superior, se los dejó en oscuridad por 10 minutos y luego se registró la distribución a cada lado. En total se realizaron 10 réplicas para cada compuesto y para el control. Tanto los aceites esenciales como el DEET mostraron efecto repelente $(\mathrm{p}<0.05)$ sobre T. trivittatus. Estos resultados nos impulsan a profundizar en este tipo de estudios con el fin de poder intervenir en ambientes donde no es conveniente el uso de insecticidas.

\title{
Bioelectroestimulación en escorpiones de importancia médica en Argentina
}

\author{
Emiliano A. Lértora, Daniel I. J. Hermann, Ignacio X. Schuster, Osvaldo Carrera \\ Instituto Nacional de Producción de Biológicos - Administración Nacional de Laboratorios e Institutos de Salud - "Dr. Carlos G. \\ Malbrán”, Argentina. elertora@anlis.gov.ar ; dhermann@anlis.gov.ar ; ischuster@anlis.gov.ar; ocarrera@anlis.gov.ar
}

Dentro de los arácnidos de importancia medica en Argentina se encuentran los escorpiones del genero Tityus, los cuales tienen una amplia distribución en Argentina, siendo los principales causantes de envenenamientos en nuestro territorio. Dentro de su telson poseen un par de glándulas de veneno con una potente neurotoxina capaz de bloquear o modular diferentes tipos de canales iónicos, principalmente en el sistema nervioso autónomo, provocando la liberación masiva de neurotransmisores. Se obtienen los ejemplares de escorpiones por parte de diversos centros de Epidemiologia y Zoonosis del país y se mantienen en cuarentena. Se ubican en cajas plásticas con sustrato, corteza de árbol, bebederos y refugios, sin alimentación durante 30 40 días. Luego mediante un equipo bioestimulador eléctrico de bajo voltaje se aplica una descarga controlada a cada uno de los escorpiones, previamente insertando el telson en un capilar de 50 microlitros, obteniendo veneno puro que se almacena en freezer para su posterior uso en pruebas y producción del antiveneno especifico. La alimentación de los escorpiones consiste en grillos y cucarachas criadas en nuestro laboratorio, se realiza siguiendo un cronograma posterior a la fecha de ordeñe, para garantizar una mayor cantidad y calidad de veneno. En el periodo 2015-2016 se realizaron un total de 2731 ordeñes. Este método de 
bioestimulación eléctrica nos brinda una optimización cualitativa y cuantitativa de la obtención del veneno puro, comparado al método estándar basado en el homogenato de télsones, el cual presenta proteínas ajenas al veneno puro.

\title{
Metodología de extracción de veneno de las arañas del género Phoneutria para producción del antiveneno específico
}

\author{
Emiliano A. Lértora, Daniel I. J. Hermann, Ignacio X. Schuster, Osvaldo Carrera \\ Instituto Nacional de Producción de Biológicos - Administración Nacional de Laboratorios e Institutos de Salud - "Dr. Carlos G. \\ Malbrán”Av. Vélez Sarsfield 563, Ciudad Autónoma de Buenos Aires, Argentina. elertora@anlis.gov.ar ; dhermann@anlis.gov.ar ; \\ ischuster@anlis.gov.ar ; ocarrera@anlis.gov.ar
}

Las arañas del género Phoneutria son unas de las tres especies de importancia médica en la Argentina, las cuales se distribuyen en el norte de nuestro país. La extracción del veneno de las mismas, se realiza mediante un dispositivo que permite la obtención del veneno del animal bajo anestesia y recuperación del mismo luego del ordeñe, permite obtener además un veneno puro, de mejor calidad que el obtenido por homogenato de glándulas (método utilizado anteriormente). La implementación de este dispositivo mejoro la seguridad del operador y del animal, disminuyendo los riesgos de accidentes por mala manipulación y el estrés que ocasiona al mismo. Se utilizaron arañas del género Phoneutria recolectadas en la localidad de El Soberbio, provincia de Misiones. Las recolecciones se realizaron en los meses de Mayo de 2014, Diciembre de 2014, Febrero 2015, Marzo de 2015, obteniendo una cantidad total de 24 ejemplares. Los animales se transportaron vivos al aracnario del INPB, donde fueron alojados en contenedores especiales y alimentados con invertebrados criados dentro de la institución. Para la extracción de veneno se trabajó con las arañas vivas, expuestas 1 minuto en una cámara de gas con $\mathrm{CO} 2$, con el fin de inmovilizarlas. Mediante un equipo bioestimulador eléctrico de bajo voltaje se aplica una descarga controlada obteniendo así un veneno puro, además la utilización del dispositivo disminuyo notablemente el estrés sufrido por el animal y el riesgo de los operadores respecto al método anterior. En Abril de 2016 se dio comienzo a las pruebas necesarias para la obtención de un antiveneno de calidad y a partir de Julio de 2017 se produjeron 2000 viales de antiveneno especifico que se distribuyeron en las provincias con mayor riesgo de sufrir accidentes aracnídicos causados por arañas del género Phoneutria. 


\title{
Serie de Casos Clínicos: experiencia en uso de Suero Antiloxosceles laeta
}

\author{
Mariana Remes Lenicov ${ }^{1}$, Mariela Schiaffino ${ }^{1}$, Fernanda Lamonega ${ }^{1}$, Claudia A. González $^{2}$, \\ Roxana A. Bertrand ${ }^{2}$, Cecilia González ${ }^{3}$
}

\begin{abstract}
${ }^{1}$ Centro Provincial de Referencia en Toxicología de La Provincia de Buenos Aires. Hospital Especializado en Toxicología y Salud Mental, La Plata, Buenos Aires, Argentina.

${ }^{2}$ Hospital de Agudos Dr. Leónidas Lucero. Unidad de Toxicología y Farmacovigilancia. Bahía Blanca, Buenos Aires, Argentina. ${ }^{3}$ Instituto Biológico Dr. Tomás Perón. Coordinación de Centros Antiponzoñosos. Ministerio de Salud de La Provincia de Buenos Aires, Argentina. ceprotox@gmail.com, gonzalezca68@hotmail.com,roxbertrand@hotmail.com,centrosantipon@gmail.com

El loxoscelismo es un cuadro clínico causado por la mordedura de araña Loxosceles laeta la responsable principal de dichos accidentes en Argentina. Se le atribuye a la esfingomielinasa-D del veneno, las extensas lesiones cutáneas con importante pérdida de tejido luego de la inoculación. Los cuadros viscerohemoliticos tienen una alta morbimortalidad producto de la intensa hemólisis y fallo renal. Las guías nacionales argentinas recomiendan aplicar precozmente el suero específico antiloxosceles. Realizamos una búsqueda retrospectiva multicéntrica para mostrar, como ejemplo del manejo habitual, una serie de casos de loxoscelismo atendidos en Hospitales de la Provincia de Buenos Aires que recibieron durante la evolución del cuadro clínico el suero específico antiloxosceles laeta. El tiempo transcurrido hasta la aplicación del suero osciló entre 12 y 36 horas siendo la evolución favorable en to dos los casos. En enfermedades de baja ocurrencia y en ausencia de ensayos controlados, la serie de casos clínicos pueden proporcionar información útil para la toma de decisiones. En Argentina la aplicación sistemática del suero específico en casos de loxoscelismo no ha demostrado tener efectos adversos graves como lo sugieren algunas publicaciones. Además se encuentra avalada por el Ministerio de Salud de la Nación y se utiliza desde hace más de diez años por el Centro de Referencia en Toxicología de la Provincia de Buenos Aires, demostrando ser eficaz disminuyendo la morbimortalidad de dicho envenenamiento, mejorando la calidad de vida de los pacientes afectados y reduciendo los gastos en Salud Pública que las mismas representan.
\end{abstract}

\section{Relevamiento de escorpiones de interés sanitario en Ciudad Autónoma de Buenos Aires (CABA)}

\author{
Sergio G. Rodríguez Gil ${ }^{1}$, Julieta V. Sganga ${ }^{2}$, Alejandra del C. Valverde ${ }^{2}$, María \\ M. Gonzalez², Mónica S. Iglesias ${ }^{2}$ \\ ${ }^{1}$ Centro de Estudios Parasitológicos y de Vectores (CEPAVE - CONICET - UNLP) Facultad de Ciencias Naturales y \\ Museo, Universidad Nacional de La Plata. sergiorodriguezgil@cepave.edu.ar. \\ ${ }^{2}$ Laboratorio de Artrópodos. Departamento de Biodiversidad y Biología Experimental, Facultad de Ciencias Exactas y \\ Naturales, Universidad de Buenos Aires, Argentina. jsganga@bg.fcen.uba.ar, valverde@bg.fcen.uba.ar, \\ mariagonzalezch@gmail.com, iglesias@bg.fcen.uba.ar
}


En el marco del convenio entre el Gobierno de la Ciudad Autónoma de Buenos Aires (GCABA) y la Facultad de Ciencias Exactas y Naturales (FCEN) de la Universidad de Buenos Aires (UBA), se inició una prospección de escorpiones en el distrito de manera sistemática. El procedimiento de recolección de datos se organizó siguiendo distintas metodologías. Por un lado, se están realizando encuestas domiciliarias por comunas a partir de calles y avenidas determinadas a priori. Durante estos recorridos se seleccionan al menos 5 locaciones (viviendas, edificios, negocios, etc.) al azar, por cuadra y se procede al timbreo en cada vereda, cuadra de por medio. Se registra en planillas si fueron vistos escorpiones en el lugar y se reparten folletos informativos. Actualmente, se hallan relevadas 8 de las 15 comunas que forman parte de la Ciudad de Buenos Aires (CABA). Otro método es el muestreo nocturno en espacios públicos (parques, cementerios, etc.) y redes de subterráneos utilizando luces UV y trampas pitfall. El tercer método utilizado es a partir de denuncias telefónicas realizadas por los ciudadanos al GCABA, al laboratorio de Artrópodos de la FCEN-UBA o a través de una página web creada a tal efecto. La información recolectada hasta el momento muestra que todos los escorpiones capturados pertenecen a una sola especie, Tityus trivittatus, que concuerda con los casos clínicos de los que se tenía conocimiento. También se han podido detectar nuevas zonas en las que no se tenían registros previos de la presencia de escorpiones. A partir de los datos obtenidos a través de estas metodologías se podrán elaborar mapas de distribución, detectar hot spots y establecer lugares prioritarios para organizar campañas de prevención de Escorpionismo y de promoción de la salud en el ámbito de CABA.

\title{
EXTENSIÓN
}

\section{Evolución y evaluación de la aparición de escorpiones en la ciudad de La Plata (Buenos Aires, Argentina)}

\author{
Luis Giambelluca, Sandra González, Guillermo Reboredo, Sergio Rodríguez Gil, y \\ Alda González \\ Centro de Estudios Parasitológicos y de Vectores (CEPAVE) (CONICET-UNLP), Facultad de Ciencia Naturales y Museo, \\ Universidad Nacional de La Plata, Argentina. giambelluca@cepave.edu.ar, san.gonzalez.san@gmail.com, \\ grreboredo@yahoo.com.ar, sergio.rodriguezgil@gmail.com, asgonzalez@cepave.edu.ar
}

En los últimos años se han incrementado las consultas realizadas en el laboratorio de Aracnología del CEPAVE (CONICET-UNLP), debido al aumento en la aparición de escorpiones en distintas zonas de la ciudad de La Plata. Las especies de consulta son Bothriurus bonariensis y Tityus trivittatus. La primera asociada a zonas rurales- periurbanas y la segunda a zonas urbanas. Se trabajó con el material producto de las 129 consultas realizadas por parte de la comunidad, desde el año 2008 al 2018. Considerando las dos especies presentes, el año con mayor registro fue el 2013, año que coincide con la gran inundación que ocurrió en La Plata. La 
población de $T$. trivittatus presenta una distribución agregada, con dos zonas de gran concentración, una correspondiente a la zona urbana este de la ciudad y otra en la zona urbana del barrio Los Hornos al oeste de la ciudad, y una distribución periférica con muy pocos ejemplares. Esta especie presentó dos morfos (todas hembras), predominando uno en cada zona. Del análisis estacional surge que abril fue el mes más abundante de $T$. trivittatus. La población del barrio los Hornos no tuvo registros en enero, julio, agosto y diciembre, mientras que en la zona este hubo registros todo el año, excepto en el mes de setiembre.

\title{
Qué sabe usted de arácnidos?: mitos
}

\author{
Sergio Rodríguez Gil, Luis Giambelluca, Cristina Scioscia, Guillermo Reboredo y \\ Alda González \\ Centro de Estudios Parasitológicos y de Vectores (CEPAVE) (CONICET-UNLP), Facultad de Ciencia Naturales y Museo, \\ Universidad Nacional de La Plata, Argentina. sergio.rodriguezgil@gmail.com, giambelluca@cepave.edu.ar, \\ crisscio@yahoo.com.ar, grreboredo@yahoo.com.ar, asgonzalez@cepave.edu.ar
}

Las arañas son animales que en general no son apreciados por el ser humano. No obstante suelen formar parte del folclore de cada país. Nuestra hipótesis de trabajo fue que la gente le teme a las arañas porque poco saben sobre ellas y es por esto que abundan los mitos. A partir de esta premisa nos propusimos evaluar las creencias erróneas y preconceptos arraigados en la población. Se diseñó el dominio quesabedearacnidos.com.ar, en Joomla se acopló la encuesta desde Google Drive con un formulario asociado a una planilla de cálculo. Se trabajó con 1593 encuestas, las cuales figuraban 27 creencias populares o mitos. Al evaluar cada mito y comparar las respuestas por sexo, 20 de los casos mostraron diferencias significativas con $\mathrm{p}=0,005$, en tanto que las 7 restantes no mostraron diferencias. Al agrupar todas las respuestas comocorrectas e incorrectas (independientemente si eran verdaderas o falsas) y analizar si existía diferencia entre los sexos, estas mostraron diferencias no significativas. Si se considera el total de respuestas correctas como un indicador de conocimiento de los participantes, el conocimiento general se ubicaría en 57,44 (varones 61,77 y mujeres 56,43 ). 